\title{
Facioscapulohumeral muscular dystrophy: genetics, gene activation and downstream signalling with regard to recent therapeutic approaches: an update
}

Teresa Schätzl ${ }^{1}$, Lars Kaiser ${ }^{1,2}$ and Hans-Peter Deigner ${ }^{1,3,4^{*}}$ (D)

\begin{abstract}
Whilst a disease-modifying treatment for Facioscapulohumeral muscular dystrophy (FSHD) does not exist currently, recent advances in complex molecular pathophysiology studies of FSHD have led to possible therapeutic approaches for its targeted treatment. Although the underlying genetics of FSHD have been researched extensively, there remains an incomplete understanding of the pathophysiology of FSHD in relation to the molecules leading to DUX4 gene activation and the downstream gene targets of DUX4 that cause its toxic effects. In the context of the local proximity of chromosome $4 \mathrm{q}$ to the nuclear envelope, a contraction of the D4Z4 macrosatellite induces lower methylation levels, enabling the ectopic expression of DUX4. This disrupts numerous signalling pathways that mostly result in cell death, detrimentally affecting skeletal muscle in affected individuals. In this regard different options are currently explored either to suppress the transcription of DUX4 gene, inhibiting DUX4 protein from its toxic effects, or to alleviate the symptoms triggered by its numerous targets.
\end{abstract}

Keywords: Facioscapulohumeral muscular dystrophy (FSHD), Double Homeobox 4 (DUX4), Epigenetic, Downstream signalling, Treatment strategies

\section{Introduction}

Facioscapulohumeral muscular dystrophy (FSHD) is estimated to be the second most prevalent dystrophy after Duchenne muscular dystrophy [1] and affects approximately 870,000 people worldwide [2, 3]. However, the number of individuals with FSHD may be significantly higher because of undiagnosed cases [4]. FSHD is a genetic disease with symptoms that develop between infancy and late adulthood, and generally in the second decade of life [5]. Early onset can be seen as a marker for disease severity [6] and the disease is primarily \footnotetext{
78054 Villingen-Schwenningen, Germany

*Correspondence: hans-peter.deigner@hs-furtwangen.de ${ }^{1}$ Institute of Precision Medicine, Medical and Life Sciences Faculty, Furtwangen University, Jakob-Kienzle-Straße 17,

Full list of author information is available at the end of the article characterized by asymmetric, progressive muscle weakness [7]. FSHD is inherited in an autosomal dominant pattern and the rate of de novo cases is estimated to be around $30 \%$. There also appears to be a high frequency of somatic mosaicism [8]. Two types of FSHD have been reported, FSHD1 and FSHD2, which induce the same phenotype (see "Genetics") [9]. In general, FSHD initially affects the upper half of the body, specifically the in "face (facio), shoulder girdle (scapulo), and upper arms (humeral)" [4]. As illustrated in Fig. 1, early symptoms are scapular winging (scapula alata) and inability to raise the arms above shoulder height. This is accompanied by problems in closing eyes or moving lips due to particularly affected musculi orbicularis oculi, oris and zygomaticus [10]. 


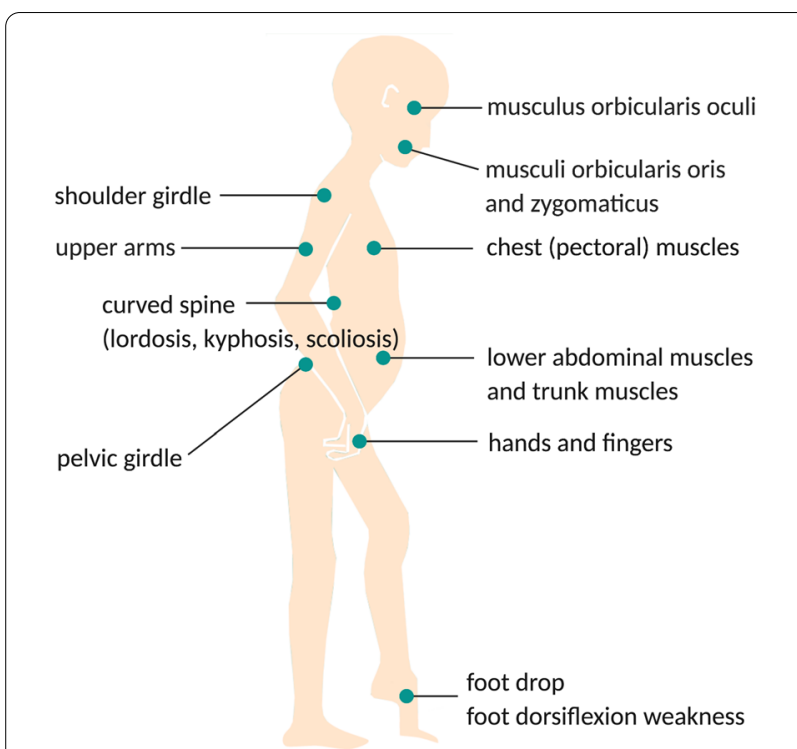

Affected muscles are generally involved asymmetrically regarding the left-right body axis

Fig. 1 Overview of affected muscles in FSHD. The symptoms tend to start at the upper half of the body and then spread to lower body parts involving the pelvic girdle and the leg muscles. There is a high degree of clinical variability in disease severity and affected muscles are generally involved asymmetrically regarding the left-right body axis. In some cases, patients with foot drop can be supported by ankle-foot orthotics (AFOs) and knee-ankle-foot orthotics (KAFOs) [236]. Surgery to attach the scapula to the ribcage can enhance arm motion or alleviate pain [237-239]

FSHD subsequently spreads to several other muscle areas. The disease can affect the distal leg muscles (by weak foot dorsiflexion), the abdominal wall and trunk muscles, and the pelvic muscles resulting in foot drop, difficulty when climbing stairs, and problems when straightening up from a horizontal position, respectively. Although FSHD is a slowly progressing muscle disorder [11], the associated physical limitations can be significant [9]. Moreover, respiratory issues-involving weak diaphragm and the expiratory abdominal muscles-are common in FSHD patients [12]. Respiratory function should therefore be evaluated during periodic clinical visits [13]. Nevertheless, most patients with FSHD have a normal life expectancy in contrast to those with Duchenne muscular dystrophy and Myotonic dystrophy [9]. FSHD generally begins at an approximate age of 20 years $[14,15]$. The phenotype can range from minor restrictions to severe disability with disease severity varying widely between individuals [16]. This may explain the results of a cross-sectional study, by Hamel et al. (2019), involving 328 participants with FSHD which showed a high percentage of people experiencing a changed body image as disease burden (91.6\%) besides factors such as physical limitations (96.9\%) and pain (87.7\%). Also, a substantial proportion (93.8\%) of FSHD patients experience fatigue that significantly impacts their quality of life $[17,18]$. Moreover, a qualitative study by Schipper et al. (2016), in which 25 FSHD patients suffering from severe fatigue (measured using the checklist individual strength (CIS) fatigue questionnaire) were interviewed, concluded that FSHD has a high influence on "participation, social contacts and quality of life" [19]. Chronic pain is another commonly described FSHD symptom [20], and is caused by overburdened joints and (asymmetric) muscle wasting that induces limb misalignments [21]. Nevertheless, a specific patient's course of disease progression and muscle weakness is predictable because disease severity correlates with the number of D4Z4 repeats at chromosome 4 (see "Genetics"). In fact, FSHD muscle weakness and progression is variable, even amongst siblings or between genders [4].

In case of early onset phenotype, which is estimated to occur in approximately $10 \%$ of disease carriers [22], patients usually show symptoms before the age of 5 [23] and are severely affected with rapid disease progression, marked muscular wasting, and weakness [24]. In this regard, comprehensive data on the clinical phenotype is missing. However, Goselink et al. (2017) conducted a systematic literature search on the clinical characteristics of early onset FSHD covering 43 articles with data on 227 patients. They found out $40 \%$ of patients were wheelchair-bound at the age of 18 . Moreover, FSHD was frequently associated with extramuscular involvements, encompassing "hearing loss (40\%), retinal abnormalities (37\%) and developmental delay (8\%)" showing a negative correlation between D4Z4 repeat size and disease severity, which is comparable with adult-onset FSHD (see "Genetics"). Other research on the infantile phenotype showed symptoms such as cardiac arrhythmia, respiratory insufficiency, and difficulties with swallowing [25]. Therefore, a bilevel positive airway pressure machine or ventilator to initially manage symptomatic respiratory issues may be necessary [4].

\section{Genetics}

There are two genetically distinct forms of FSHD known as FSHD1 and FSHD2. Although genetically distinct, both are the result of the inappropriate expression of a gene called Double Homeobox 4 (DUX4) gene [26]. A 3.3 kilobase $(\mathrm{kb})$ tandemly repeated sequence (D4Z4) located on chromosome $4 \mathrm{q} 35$ carries the gene [27]. It is usually expressed during embryogenesis, where it activates an early developmental program that marks the cleavage stage of embryogenesis [28-30] and is then effectively silenced [31]. While DUX4 is expressed only in the testis [32] and in the thymus at low levels [33], it 
has detrimental effects when expressed in skeletal muscle resulting in FSHD [34].

Throughout the human genome there is a number of D4Z4-like sequences, mostly accompanying acrocentric chromosomes [35]. Also, a very homologous and equally polymorphic D4Z4 repeat is located on chromosome $10 \mathrm{q} 26$ ( $~ 98 \%$ similarity to the $4 \mathrm{q} 35$ locus), which has never been associated with FSHD [36] as this chromosome has no permissive single nucleotide polymorphism (SNP) in the DUX4 Polyadenylation Signal (PAS) (see "DUX4 gene expression") [26]. However, translocations between chromosomes 4 and 10 have been reported [37, 38], which complicates diagnosis (see "Methods of diagnosis"). Healthy individuals carry 11-100 D4Z4 repeats that are positioned within heterochromatin. Therefore, DUX4 is not transcribed in somatic tissues [26]. FSHD1 patients show a reduced number of $1-10$ repeats referred to as a "contraction" [9]. This contraction correlates with a "loss of repressive epigenetic marks" regarding methylation levels within the D4Z4 macrosatellite, enabling small molecules to trigger the ectopic expression of the DUX4 gene in muscle cells [39]. The hypomethylation in FSHD is restricted to the D4Z4 repeat as it is not detected in the region proximal to the repeat [40].

Ninety-five percent of patients with FSHD have FSHD1, with the remaining percentage having FSHD2 [41]. In FSHD2 there is no contraction of the D4Z4 repeats [42] as the 4q35 locus contains 11-20 repeats. However, the number of repeats is not always decisive as some patients are excluded from this definition [43, 44]. In the case of FSHD2, a mutation in the Structural Maintenance of Chromosomes flexible Hinge Domain Containing 1 (SMCHD1) gene (> 80\% of FSHD2), or (rarely) in the De Novo Methyltransferase 3B (DNMT3B) gene leads to the hypomethylation of the D4Z4 array thereby enabling the aberrant expression of the DUX4 protein $[45,46]$. Recently, Hamanaka et al. (2020) also identified LRIF1 as disease gene for FSHD2 [47] (see "FSHD2 and related diseases").

A lower repeat number correlates with a more severe disease progression in patients with FSHD1 and 1-6 repeats. Most of the epigenetic factors that cause FSHD1 symptoms in patients with 7-10 repeats are unknown [48], and rare cases can be induced by an $S M C H D 1$ mutation although $S M C H D 1$ is commonly related to FSHD2 [49]. However, whilst there are the two major allelic forms $4 \mathrm{qA}$ and $4 \mathrm{qB}$, only the former is associated with the disease. As illustrated in Fig. 2, the 4qA haplotype is further classified based on Simple Sequence Length Polymorphisms (SSLPs) proximal to the D4Z4 repeat. Only the SSLP variant 4A161 and the rare variants 4A159 and 4A168 were shown to correlate with D4Z4 reduced alleles in FSHD patients [36]. The 4qA sequence carries a $9 \mathrm{~kb}$ beta-satellite repeat region-"immediately distal to the D4Z4 repeat" - which cannot be found in $4 \mathrm{qB}$ [11]. The variant ATTAAA was discovered in the pLAM1 sequence of the 4qA alleles. This provides a PAS enabling the expression of the most distal copy of the DUX4 gene $[26,50]$.

\section{Methylation levels of the D4Z4 macrosatellite in FSHD}

FSHD methylation levels encompass both a low CpG methylation at D4Z4 DNA correlating with a reduced number of D4Z4 units [51-53] and a specific loss of H3K9me3 followed by the loss of heterochromatin protein 1 (HP1) and cohesin binding at D4Z4. This suggests a more relaxed chromatin structure [54]. There seems to be a relationship between DNA hypomethylation and clinical severity in patients with an additional mutation in $S M C H D 1$ and DNTM3B $[46,55]$. Furthermore, there are indications that infantile FSHD patients show extreme epigenetic dysregulation of the FSHD locus [56]. To date, different methylation analyses have been conducted [51$53,57,58]$. However, the comparison of results proves difficult due to the evaluation of GpGs within different regions of the $\mathrm{D} 4 \mathrm{Z} 4$ array and the use of different statistical tools. While Lemmers et al. (2015) consider the D4Z4 array as a linear string of mathematical units to define global methylation [48, 52], Calandra et al. (2016) highlight the potential of one single CPG to distinguish individuals and point to the CpGs distal to the D4Z4 array [57]. Other study findings doubt that D4Z4 methylation mirrors the clinical expression of FSHD [59] and indicate that measurement of this epigenetic mark must be interpreted with caution in clinical practice [58]. According to the hypothesis of Gaillard et al. (2019), FSHD chromatin landscape is not inherited but progressively installed upon differentiation. Based on confocal imaging the authors showed long-distance interactions between the D4Z4 array, the telomere and the nuclear lamina (see "FAT1 in the context of long distance interactions") [60]. The nuclear lamina impact on global chromatin architecture is poorly understood. Experiments in mice and Drosophila have already shown its major role in chromatin organisation shaping the 3D genome [61,62]. In this context, as chromatin regulation involves long-distance interactions [63], the entire location of the chromosome 4 within the nucleus should be looked at more closely.

\section{FSHD2 and related diseases}

FSHD types 1 and 2 show a common pathomechanism that results from the stabilization of the DUX4 transcript. Prerequisites for FSHD2 are a mutant SMCHD1or (rarely) $D N M T 3 B$ allele and a permissive $4 \mathrm{qA}$ allele $[45,46]$. In this case, the D4Z4 repeats on both $4 \mathrm{q} 35$ copies and on chromosome 10 are hypomethylated 


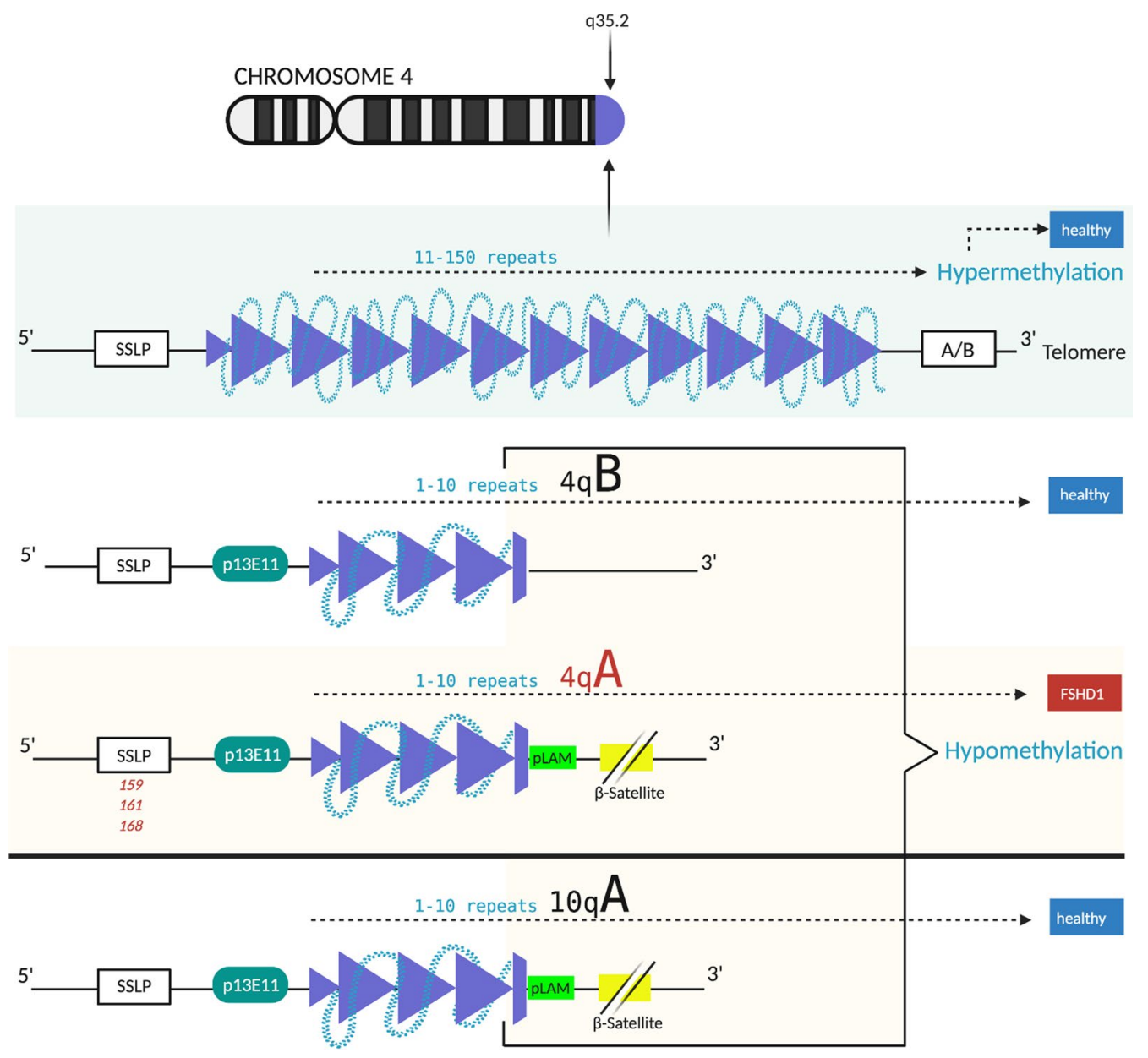

Fig. 2 Chromosome 4q35.2 in healthy- and in FSHD1-individuals. 11-150 D4Z4 repeats (dark blue) leading to a high methylation level within the D4Z4 macrosatellite (light blue), which represses the transcription of DUX4. There are two possible haplotypes A and B, which are equally common and a Simple Sequence Length Polymorphism (SSLP) proximal to the D4Z4 repeat further classifying haplotype A or B [36]. FSHD only occurs in individuals, which carry the 4qA allele. People with contraction and thus minor methylation at chromosome $4 \mathrm{q} 35$ are either also carrying $4 \mathrm{qA}$ and have FSHD or $4 \mathrm{qB}$ and are healthy. The 4qA haplotype is further classified based on SSLPS proximal to the D4Z4 repeat. Only the common SSLP variant 4A161 and the rare variants 4A159 and 4A168 are reported to correlate with D4Z4 reduced alleles in FSHD patients. This example: 1-10 repeats/ FSHD1; the same conditions of a permissive Haplotype A apply for FSHD2 [36]. Haplotype A further carries the pLAM1 sequence (light green) and a beta-satellite repeat region immediately distal to the D4Z4 repeat (yellow). Detection is depicted via Southern Blot probe p13E-11 (dark green). Chromosome 10q26 is also illustrated as it shows nearly 100\% similarity to the 4q35 locus [36]

[64]. Moreover, Hamanaka et al. (2020) recently identified LRIF1 as a rare FSHD2 disease gene, which was also shown to bind to the D4Z4 repeat array. Knockdown of the LRIF1 long isoform resulted in DUX4 expression as a result of partial chromatin relaxation. Interestingly, while almost all patients with FSHD2 show monoallelic mutations in SMCHD1 or DNMT3B, LRIF1 mutation was demonstrated to be biallelic. According to the authors, LRIF1 mutations are a rare reason for FSHD and should thus only be considered in FSHD2 when tested negative for SMCHD1 mutations [47].
Interestingly, D4Z4 hypomethylation is not specific to FSHD. In this regard, mutations of the two FSHD2 modifiers-SMCHD1 and DNMT3B-could be reported in other diseases as well. Missense mutations in SMCHD1 were shown to cause Bosma arhinia microphthalmia syndrome (BAMS) $[65,66]$, which is a very rare disease characterized by complete absence of the nose and possible ocular defects [66]. In contrast to FSHD2 individuals, BAMS patients show no signs of muscular dystrophy while SMCHD1 mutations in FSHD2 are not associated with craniofacial defects, which are characteristic for BAMS. Both diseases induce identical transcription of 
the DUX4 gene and increased expression of some of its target genes. However, there are different mutations in $S M C H D 1$, which seem to have no impact on transcription, but on the epigenetic organisation of D4Z4, thus showing entirely different phenotypical outcomes [59]. SMCHD1 is involved in repairing DNA double-strand breaks [67] and in the epigenetic regulation of different genes particularly mediated by the histone mark H3K9me3 [68]. Furthermore, it plays a role in inactivating the $\mathrm{X}$ chromosome. In case of FSHD2 or BAMS, mutations do not affect $\mathrm{X}$ inactivation. While in most BAMS patients mutations induce gain of ATPase activity, there is a loss of function in FSHD2 regarding remethylation [59] (see "The ATPase domain of BAMS and FSHD2"). Intriguingly, the latter was found to be similar to what is observed in cells from patients with immunodeficiency, centromeric instability, and facial anomalies (ICF) syndrome $[59,69]$ as one of its subtypes, ICF1, arises from DNMT3B mutations. ICF1 is associated with reduced levels or absence of serum immunoglobulins [70] and it affects facial appearance [46]. In contrast to FSHD2, which is caused by dominant mutation of DNMT3B, ICF1 is inherited in an autosomal recessive pattern. Whereas heterozygous ICF1-mutation carriers neither show any muscle dystrophy nor present immunological abnormalities, in FSHD2 the absence of an immunological phenotype could be described by the presence of one wild-type DNMT3B allele. A low D4Z4-repeat size and a permissive $4 \mathrm{qA}$ allele containing a DUX4 PAS were reported to facilitate $D U X 4$ expression when both $D N M T 3 B$ alleles are mutated. However, in this case, next to the described features of ICF1, muscle weakness has never been reported. According to van den Boogaard et al. (2016), the short life expectancy of ICF1 individuals might be the reason for the lacking FSHD2 phenotype [46].

\section{The ATPase domain of BAMS and FSHD2}

In FSHD2, specific SMCHD1 mutations have been described across the whole coding sequence [59], whereas mutations inducing BAMS are localized within exons 3 to 13 [66]. In this context, the ATPase domain of SMCHD1 is an overlapping area of mutations in both diseases. However, whilst FSHD2-specific variants are typically localised in the ATP binding pocket, BAMS variants are most often positioned at the dimer interface-being an area that may be essential for the dimerisation of the ATPase domain [71]. However, overlapping variants have also been discovered amongst the different mutations. Nevertheless, the individual diseases seem to be mutually exclusive as studies of extended FSHD2 families carrying BAMS-specific variants have shown no signs or symptoms characteristic for BAMS. Interestingly, one
BAMS patient with FSHD symptoms, having a moderately sized D4Z4 repeat on a 4qA allele, was found [11, 65]. Lemmers et al. (2019) suggested that BAMS might also incorporate another yet unknown locus [71]. But the mechanisms are still not fully understood and require further structural and biochemical analysis.

\section{DUX4 protein}

Tassin et al. (2013) presented a model of how an initially very low concentration of the DUX4 protein can potentiate its effects. After the DUX4 gene is activated, it is transcribed into mRNA, which is translocated into the cytoplasm domain near the activated nucleus. Then it is translated into the DUX4 protein, which carries a nuclear localization signal (NLS). It diffuses in the cytoplasm and is transported into various neighbouring nuclei. Subsequently, the cascade initiation and amplification begins, as DUX4 activates other transcription factors which are imported into neighbouring nuclei. The number of activated nuclei and expressed genes grows at every point, thereby enabling an amplification of the initial trigger [72].

Snider et al. (2010) showed in vitro that FSHD muscle expresses another splice form of DUX4 mRNA when compared with control muscle. Figure 3 shows that control muscle generates low amounts of a splice form of DUX4 encoding the amino-terminal part and both homeodomains, but it does not contain the C-terminal domain. This is referred to as DUX4-S (S for short) and is not toxic [73]. In contrast, FSHD muscle produces DUX4-FL (FL for full-lengths) mRNA that encodes the whole DUX4 protein, which contains 424 amino acids [32]. Previous in vitro studies showed that DUX4induced pathology requires both intact homeodomains and a transcription-activating domain (TAD) in the C-terminal region of the protein. Furthermore, it was found that non-toxic constructs with both homeodomains intact could act as inhibitors of DUX4 transcriptional activation, and is likely due to competition for promoter sites [74].

The two homeoboxes situated at the N-terminus of the protein are responsible for binding to the DNA. The $\mathrm{C}$-terminal domain is relevant for target gene activation and contributes to the cellular toxicity of DUX4-FL by interacting with histone acetyltransferase $p 300$ and transcriptional coactivator $C B P[75,76]$ (see "DUX4 Downstream Signalling: $\mathrm{p} 300 ")$.

Zhang et al. 2016 analysed the DNA-binding sequence specificity of DUX4 by using Chromatin ImmunoPrecipitation DNA-Sequencing (ChIP-seq) analysis and identified a consensus containing two tandem TAAT motifs (TAAT[T/C][T/C]AATCA). They showed that all four variants could be identified by $D U X 4$, but the motif 


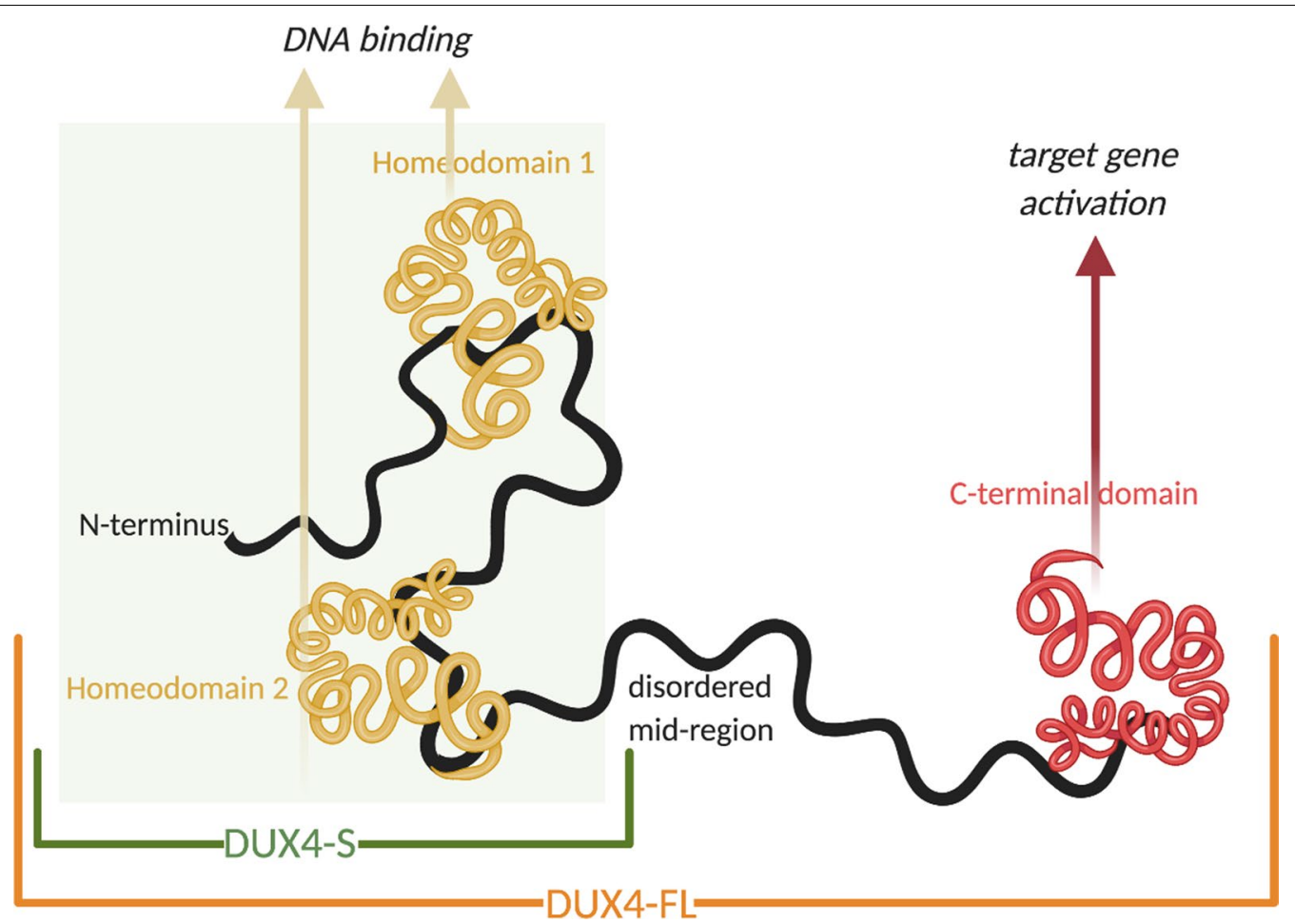

Fig. 3 DUX4-FL protein. This protein contains 424 amino acids and is expected to have well-defined tertiary structures in each of the two DNA-binding homeodomains (amino acids 19-79 and 94-154) and in the most C-terminal region (amino acids 365-424). The C-terminal region includes the transcription-activating domain (TAD) and a p300-binding domain. The region between the second homeodomain and the C-terminal domain (amino acids $\sim 155-364$ ) is predicted to be disordered. The protein contains a potential nine amino acid TAD (9aaTAD) at amino acids 371-379 (classified as a 92\% match) [74]

containing a central cytosine followed by a thymidine (TAATCTAATCA) was the most preferred by DUX4, thus having the greatest transcriptional activity in vivo [77].

\section{DUX4 gene expression}

In FSHD muscle only DUX4 from the most distal repeat unit can be expressed in a stable manner. This is due to genetic elements downstream to the repeat that are necessary for mRNA processing [32, 78]. As illustrated in Fig. 4, the DUX4-FL gene is composed of three exons. While its open reading frame (ORF) is entirely incorporated in the first exon, exon 2 and 3 are non-coding regions ( $3^{\prime}$ UTR) [39]. Besides, exon 3 is positioned outside of the $\mathrm{D} 4 \mathrm{Z} 4$ repeats. On permissive chromosomes, in the last copy of the DUX4-FL gene the third exon stabilizes the transcript due to the presence of the PAS [26, 79].

Reverse Transcription Polymerase Chain Reaction (RTPCR) and immunofluorescence studies showed a small number of myonuclei, which express relatively high levels of DUX4-FL. There is no uniform low expression level in all nuclei $[32,79]$ leading to difficulties in detecting its expression from patient samples when searching for the disease's origin [72]. Interestingly, two isoforms of DUX4-FL were discovered as a result of alternative splicing events. Snider et al. (2010) showed the existence of DUX4-FL mRNA and the DUX4-FL-3' splice form in muscle biopsies of FSHD patients. Control muscle cells did not contain noticeable amounts of DUX4-FL mRNA. $D U X 4-S$ was expressed in all control samples with the SSLP 4A161 and in some of the FSHD samples. These data demonstrate that FSHD as well as control muscle cells "actively transcribe DUX4." [32]. In the following paragraphs DUX4-FL will be referred to as DUX4 because it is considered to cause FSHD.

According to Lim et al. (2020) "the FSHD phenotype may be the cumulative result of extensive aberrant signalling across time" [80] with unpredictable bursts of expression [81]. Since DUX4 induces hundreds of different target genes, also affecting the induction of apoptosis [82] and atrophic muscle fibres [7] (see "DUX4 Downstream Signalling"), its repetitive expression over years may lead to noticeable loss of the specific muscle areas (see Fig. 1). In this regard Mariot et al. (2015) suggested, that FAT1 levels might determine which muscles 


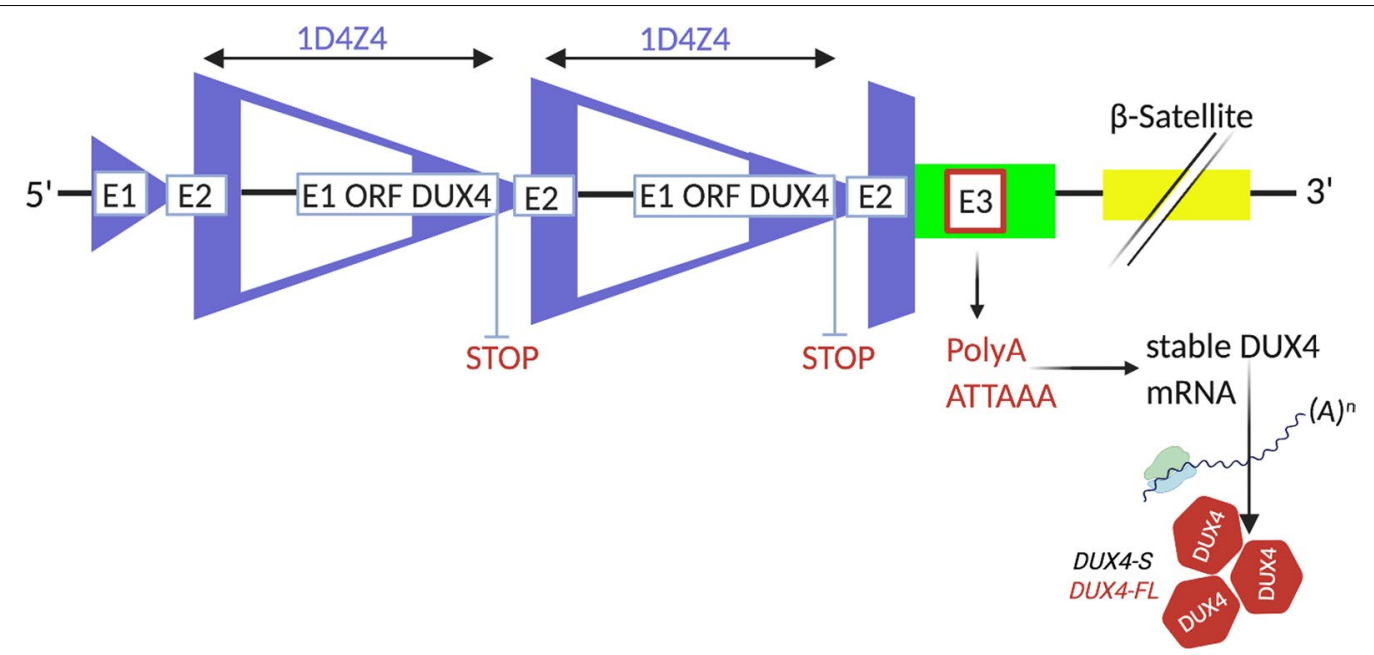

Fig. 4 Requirements for DUX4 gene expression. DUX4 expression is only possible at the most distal D4Z4 repeat of the 4qA alleles. Exon 3, which is located outside the D4Z4 repeats in the pLAM1 region is carrying the variant ATTAAA that provides a PAS enabling the expression of the most distal copy of the DUX4 gene into DUX4 mRNA and then DUX4 protein [39]. Whilst healthy individuals especially generate the non-toxic splice form of DUX4-S (encodes the amino-terminal part and both homeodomains; does not contain the C-terminal domain) [73], FSHD muscle produces toxic DUX4-FL mRNA [32]

will exhibit early and late disease onset, while DUX4 may worsen the muscle phenotype [83] (see "FAT1 in the context of long distance interactions"). Whilst the nature of DUX4 has been researched extensively and great knowledge has been gathered in the last decade, the context of genetic interaction regarding methylation levels is not fully understood and direct target genes, which bind to the DUX4 promoter, are still not fully known. Nevertheless, molecular key features of DUX4, such as exon 3 which is specifically associated with the pathogenic DUX4 transcript, could be revealed. This allows for promising treatment approaches in the context of future drug development (see "AOs" in "Molecular treatment strategies").

\section{Methods of diagnosis}

Diagnosis of FSHD is commonly performed using Southern Blotting [84] with the blot hybridization probe p13E-11 [85]. Double enzyme digestion using EcoRI and $B \ln \mathrm{I}-$ from the $4 \mathrm{q} 35$ and the $10 \mathrm{q} 26$ regions-is performed as the probe identifies two pairs of EcoRI alleles. As depicted in Fig. 5, 4q35 was found to be BlnI-resistant, whilst 10q26 is BlnI-sensitive [86-88]. EcoRI cuts at both ends thereby releasing complete D4Z4 repeat arrays with little flanking sequences. The EcoRI fragments from 10q26 are shortened to below the detection limit due to $B \ln \mathrm{I}$ [84]. Another restriction enzyme-called XapI-is also used for diagnosis of FSHD. In contrast to BlnI, XapI leaves chromosome 10-type units undigested when fragmenting chromosome 4-type D4Z4 units [36].
Both alleles of the 4q35 locus are examined whilst observing the molecular results from EDTA blood. One allele is typically normal-sized compared to healthy individuals [89], whilst the other allele contains fragments $(\leq 43 \mathrm{~kb})$ after EcoRI cleavage and fragments $(\leq 40 \mathrm{~kb})$ after EcoRI and BlnI double digestion. Morover, fragments associated with FSHD can no longer be detected after XapI cleavage. Eight and nine D4Z4 repeats (32$35 \mathrm{~kb}$ EcoRI fragment size) are currently defined as disease-associated [90-92]. Other researchers point out that 10-11 repeats $(38-41 \mathrm{~kb})$ are a "grey-zone" [93] or "borderline" [94]. However, there is consensus that repeat numbers above $12(\geq 45 \mathrm{~kb})$ are beyond the diagnostic range for FSHD1 [92, 93].

The determined EcoRI fragment size provides information about the approximate repeat number at the locus as each D4Z4 repeat of chromosome 4q35 is approximately $3.3 \mathrm{~kb}$ long. Approximate D4Z4 repeat numbers can be determined from EcoRI-fragment sizes by using the formula $[93,95,96]$ :

$$
\text { Repeats }=\frac{\text { EcoRi fragment size in } k b-5 k b \text { flanking sequence }}{3.3 k b}
$$

For FSHD2 diagnosis, methylation analysis of the D4Z4 region and $S M C H D 1$ sequencing on chromosome 18 is performed. This is done only if chromosome 4 also offers the "permissive" 4qA allele [55, 97] as FSHD2 is inherited in a digenic manner [45].

The traditional genetic FSHD diagnosis method is labour-intensive, requires a lot of time, and needs a large quantity of high-quality DNA. Therefore, whole 


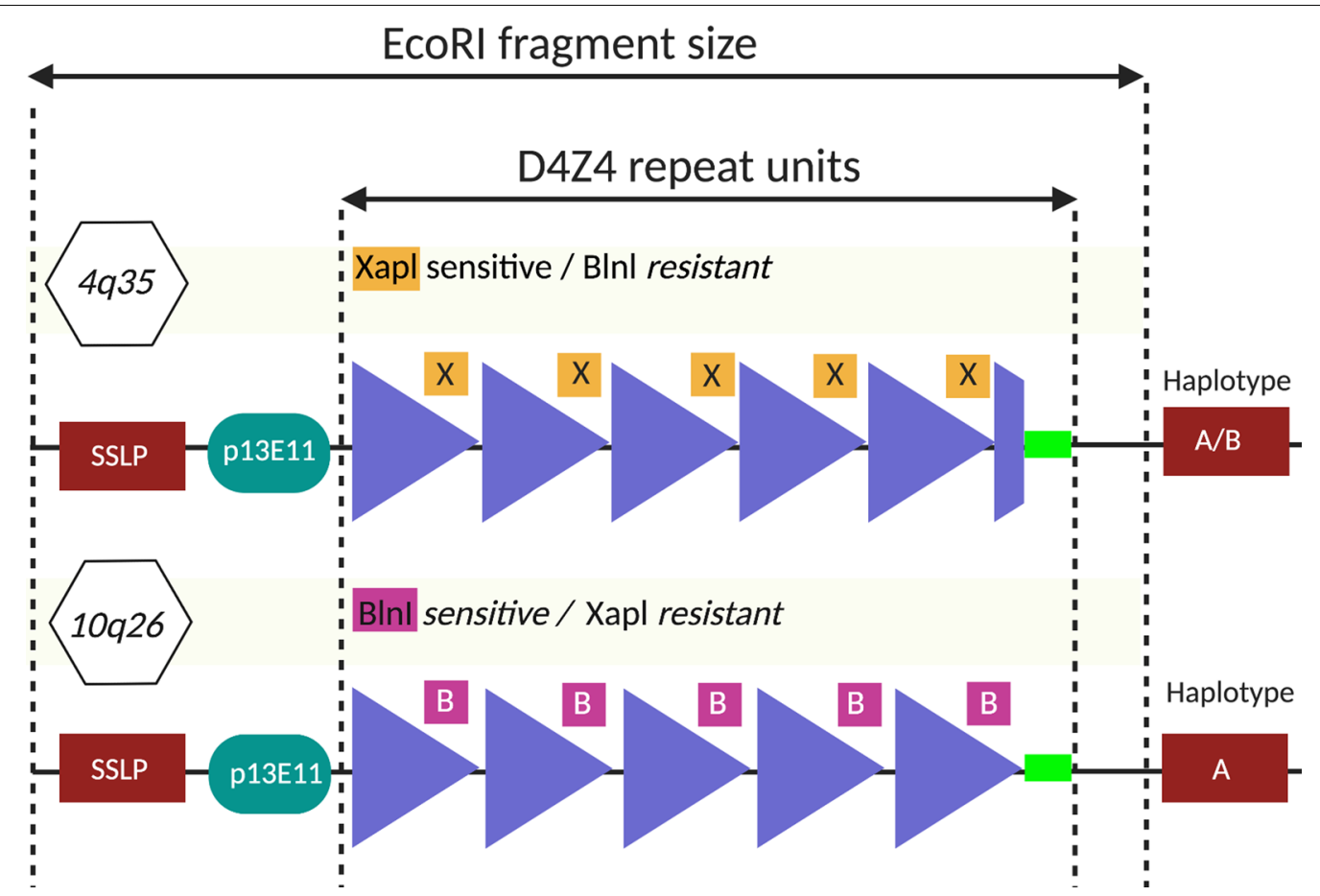

Fig. 5 Schematic representation of the methods used for FSHD1 diagnosis. The D4Z4 repeat array is indicated with triangles (in dark blue). D4Z4 repeat units on chromosomes 4 and 10 can be separated because all repeats on 10q contain BInl restriction sites (whereas all D4Z4 repeats on $4 q$ contain Xapl restriction sites) [238]

genome optical mapping is now commonly usedespecially for prenatal diagnosis. In this regard, Zheng et al. (2019) showed that Bionano optical mapping can identify the number of D4Z4 repeats and avoid interference of the 10q26 homologous region. Moreover, whole genome optical mapping combined with karyomapping results in a quick and precise diagnosis of FSHD1. Whilst the Southern Blot-method is only able to estimate the number of D4Z4 units, whole genome optical mapping is faster and more accurate [89]. However, the whole genome optical mapping technique also shows some insufficiencies as the estimated proportion of mosaicism might be less precise when several alleles differ significantly in the number of repeats [98].

Molecular combing to directly visualize allelic combinations correlating with FSHD-by identifying "somatic mosaicism, 4q-10q translocations, p13E-11 deletion, and other non-canonical modifications" [99] — has been developed for more complex disease variations [100]. Southern Blot alone may be insufficient for interpreting results in instances where translocations have been shown in both healthy individuals and FSHD patients [101]. 4qA-10qA translocations may arise and $10 \mathrm{qB}$ alleles have been reported as result from the translocation of 4qB alleles [44] due to the high level of sequence homology between chromosome $4 \mathrm{q}$ and $10 \mathrm{q}$, which facilitates inter-chromosomal exchanges [87]. Common Southern Blot is usually the first method used for the diagnosis of patients presenting FSHD phenotype, followed by Molecular Combing-which can be performed to specify results [99].

\section{Disease monitoring}

Regular neurologist or physiatrist visits help monitor the progress of FSHD, especially as there can be deficits in respiratory function over a long period of time without any severe symptoms. Furthermore, respiratory compensatory mechanisms can allow the organism to adapt to increasing amounts of carbon dioxide $\left(\mathrm{CO}_{2}\right)$ in the blood during the night due to sleep-related hypoventilation. This is known as hypercarbia (hypercapnia) [102, 103], and has been reported to cause symptoms that patients may become tolerant of, such as morning headaches, cognitive difficulties, or daytime fatigue [104]. In more severe cases when gas exchange worsens due to deficits in respiratory function, an early support with non-invasive ventilation (NIV) must be considered as there is a risk of acute respiratory failure [103]. 
Some early-onset patients may have "moderate to profound bilateral sensorineural hearing loss and sightthreatening retinal abnormalities "[105] (Coats' Syndrome [106]). In this case, it is essential to regularly check hearing and vision [105]. FSHD is a slowly progressive disease, making it difficult to evaluate modifications which may be triggered by relatively short-term treatment approaches. Therefore sensitive prognostic biomarkers are highly valuable for clinical trial design. Magnetic resonance imaging (MRI) is one technique that also indicates an early phase of muscle damage. MRI recognizes muscle injury by increased signal on short-tau inversion recovery (STIR) sequences demonstrating oedema/ inflammation which anticipates fatty replacement of single muscles. This is consistent with the suggested model of disease pathophysiology which states that bursts of DUX4 expression initiate a cascade of downstream events, also possibly encompassing an inflammatoryimmune response (see "DUX4 Downstream Signalling"). Against this background, STIR positive (STIR + ) muscle lesions have been suggested as biomarkers regarding disease activity. According to Monforte et al. (2019) examination of patients with STIR + muscles-who are thus more exposed to disease progression in a short period of time-would strongly improve the chance to discover a considerable impact of an investigational treatment. Furthermore, a higher amount of STIR + muscles at baseline was shown to anticipate deterioration at follow-up studies. This confirms the association between STIR + lesions and disease progression [107].

Electrical impedance myography (EIM) is an alternative tool that measures changes in muscle. EIM uses electrical current to identify the impedance to current flow through a specific muscle or muscle group [108]. EIM has been used in several neuromuscular diseases-including FSHD [109] - indicating its reliability [109-113]. According to LoRusso et al. (2019) EIM is "painless, requires minimal training, and does not require specific expertise in post-processing" [108]. Nevertheless, in a later study encompassing 32 patients EIM did not detect meaningful disease progression over one year in a clinically stable group of patients [108]. According to Mul et al. (2018), it is unclear whether this is because of technological limitations or the slow disease progression in that cohort of FSHD patients during the specific time frame [110].

\section{Trial readiness}

Apart from manual muscle testing (MMT) and quantitative myometry (QMT), there are no approved outcome measures which can be consistently used in clinical trials. Besides, individual functional measures may not be sensitive to disease progression over 12 months [108]. A large, international, multi-centre prospective study was therefore initiated in March 2018 in order to improve clinical trial tools and methodology in the context of drug development for FSHD [108]. The estimated completion date of the study is March 2022 (clinicaltrials.gov: NCT03458832) [114]. The 18-month long study includes 220 FSHD patients from the United States and Europe. The primary goal is to "hasten drug development for FSHD by validating two novel clinical outcome assessments (COAs) and refining clinical trial strategies" [108]. Novel COAs are the functional FSHD composite outcome measure FSHD-COM and the skeletal muscle biomarker EIM (see "Disease monitoring"). FSHD-COM encompasses 18 evaluator-administered motor tasks in the areas of shoulder/arm, hand, core/abdominal, leg, and balance function. Reliability and sensitivity to disease progression are yet to be proved $[108,115]$. The focus is set on the evaluation of the "test-retest reliability, validity, and sensitivity to disease progression, and minimal clinically important changes" of the new COAs [108]. Visits are at baseline and at months 3,12 , and 18 . Statistical methods will be further implemented at each point to specify subgroups, likely to progress over $12-18$ months in varying degrees. The aim of the study is to analyse links between demographic, genetic factors and disease progression in order to refine eligibility criteria for future clinical trials [108].

\section{FAT1 in the context of long distance interactions}

FSHD is known to affect specific muscles whilst other muscles are spared [83]. In this regard, FAT Atypical Cadherin 1 (FAT1) has been found to affect muscle morphogenesis as it influences the shape of subsets of face and shoulder muscles, partly by polarizing the direction of collectively migrating myoblasts [116]. Mariot et al. (2015) demonstrated that levels of FAT1 are lower in muscles that are affected at early stages of FSHD progression than in healthy muscles or muscles that are affected later in time. Furthermore, the authors demonstrated that FAT1 expression is independent of DUX4 [83]. The locus of chromosome 4 might therefore be particularly important as (in contrast to chromosome 10) the telomere of $4 \mathrm{q}$ is localized at the nuclear envelope. Intriguingly, mediation of interaction with the nuclear envelope was associated with genomic regions proximal to the D4Z4 repeat, such as D4S139, a variable number tandem repeat (VNTR) locus [117] that also interacts with FAT1. Gaillard et al. (2019) showed the existence of functional long distance-interactions between D4Z4, the nuclear lamina, and the telomere by using three-dimensional Fluorescent In Situ Hybridization (3D FISH). According to the authors, the 4q35 locus encompasses two topologically associating domains (ToADs) encompassing four domains connected with the nuclear lamina 


\section{NUCLEAR PERIPHERY}

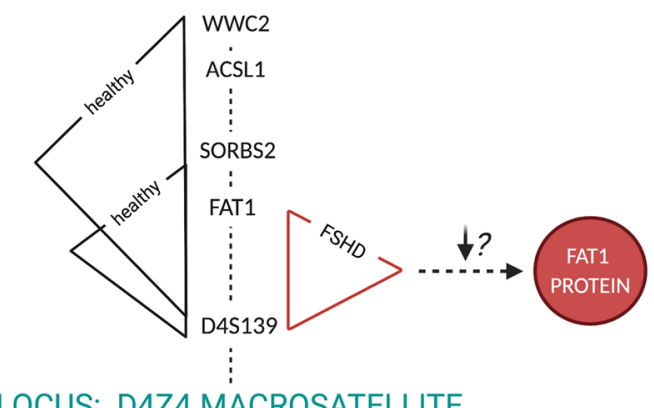

LOCUS: D4Z4 MACROSATELLITE
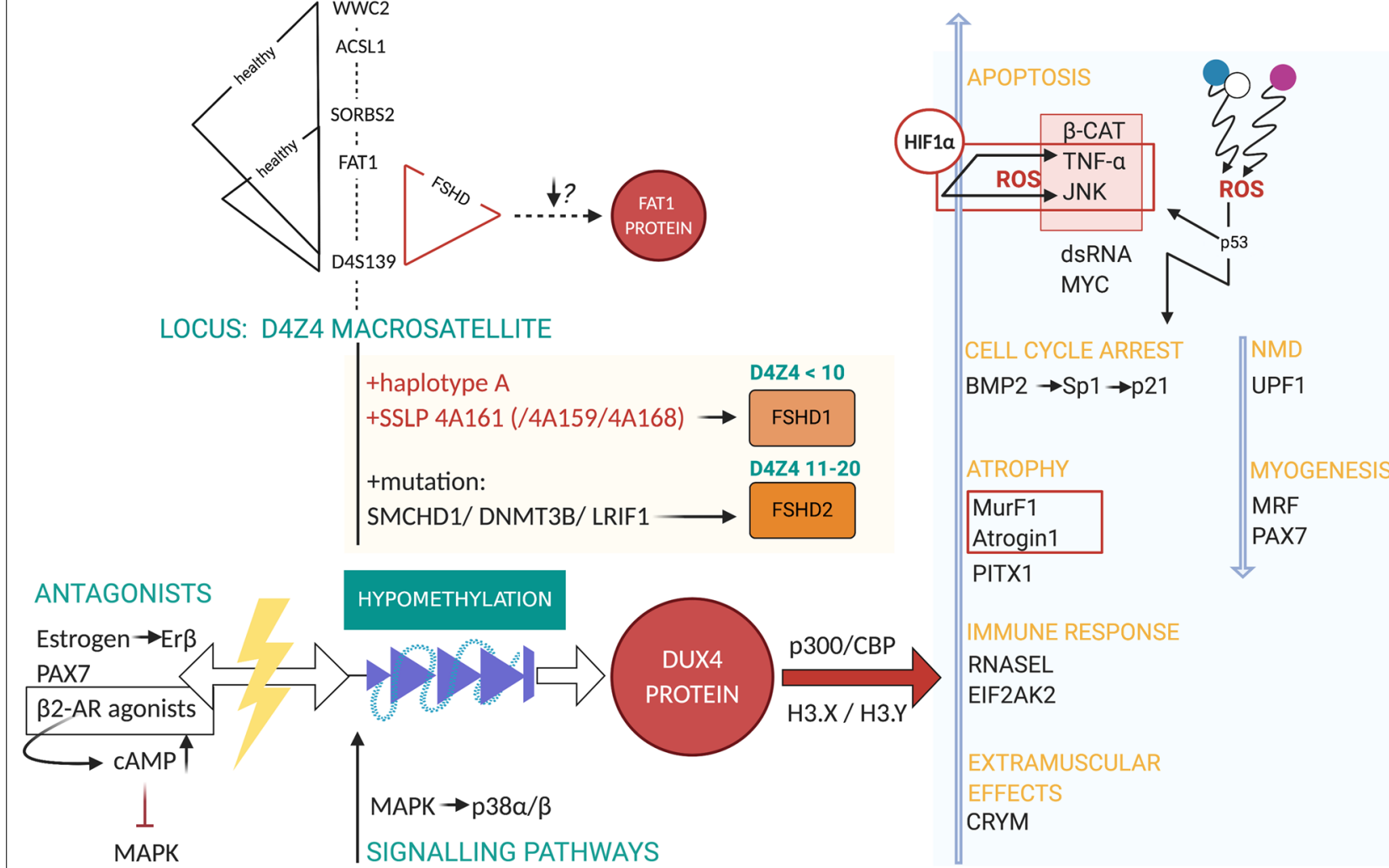

PITX

IMMUNE RESPONSE

RNASEL

EIF2AK2

\section{EXTRAMUSCULAR}

EFFECTS

CRYM

Fig. 6 Overview of DUX4 signalling. Antagonists of DUX4 are depicted on the left; Signalling pathways for DUX4 gene activation have been associated with MAPK, especially p38a/ $\beta$, bottom); DUX4 is located within the D4Z4 macrosatellite, which interacts with subtelomeric regions and the nuclear lamina via long distance-interactions, influencing (1) methylation levels and (2) gene expression. Interactions found in control cells and in FSHD are depicted at the top of the graphic. (For reasons of clarity, interactions of FSHD2 cells are not illustrated here, but are mentioned in the text.) FAT1 gene is shown to aggravate FSHD, when expressed at low levels. Muscles are more sensitive to gene deregulations and become affected earlier [83]; DUX4 generally requires help of $p 300 / C B P$ and H3.X/H3.Y for target gene expression; Depicted on the right: DUX4 expression affects multiple genes, which are either upregulated or downregulated by DUX4 protein. ROS seem to have a prominent role in disease mechanism and are probably activated directly by DUX4 itself and indirectly through further targets of DUX4

(Lamin Associated Domains, LADs), with each one overlapping with different gene areas. The most proximate LAD to D4139 overlaps with an area encompassing the FAT1 gene. It was shown that the mean distance between the D4S139 region and FAT1 was particularly higher in control cells than in FSHD cells, and that interaction of D4S139-FAT1 was restricted to FSHD. To illustrate these findings, Fig. 6 shows the different interactions found in control cells and in FSHD cells. There is an overall loss of interaction with other gene areas in the case of FSHD. (The data also demonstrated the involvement of other genes as well. For detailed information see Gaillard et al. 2019.) However, in the case of FSHD2 and the non-contracted allele of FSHD1, interactions between FAT1 and Sorbin and SH3 domain-containing protein 2 (SORBS2) could be detected further. The loss of interaction regarding the contracted FSHD1 allele [60] might contribute to FSHD1 pathogenesis as SORBS2 could be, inter alia, detected at the Z-line in skeletal muscle [118].

As D4Z4 is reported to act as transcriptional repressor CTCF-which organizes long distance-interactions between the telomere-subtelomeric regions and the nuclear lamina by distance-dependant mechanisms, it could be hypothesized that decreased levels in FAT1 expression might be the result of a changed communication between the involved genes. If so, further questions-including,"When does FAT1 expression level trigger FSHD? Is it during fetal development, after birth, or both?" [83] —as in the case of DUX4 may be answered as "both" because interaction has been shown in muscle biopsies from foetuses as well as adult individuals [60]. However, the type of interaction/ the direct impacts of interaction on protein expression have not been explored further. 


\section{DUX4 downstream signalling}

When reactivated in skeletal muscle, the early embryonic program of DUX4 [69] activates several hundreds of target genes (e.g. ZSCAN4, MBD3L2, TRIM43... [28, 119]) and initiates numerous detrimental events including the activation of the inflammatory immune response [120], the induction of apoptosis [82], atrophic muscle fibres [7], oxidative stress [121], and an altered muscle cell differentiation in myogenesis [122]. Affected FSHD muscles show fibro-fatty replacement [123, 124]. It is still unclear if inflammation displays a protective effort against the DUX4-driven damaging effects or a direct deleterious component of the DUX4 cascade [107]. Most findings described in this paragraph have been obtained in in vitro cell models or in transgenic mice overexpressing $D U X 4$. Figure 6 shows an summary of the literature findings of DUX4 pathogenesis. Also FAT1 is depicted as it is reported to influence disease severity [83].

\section{$\beta$-catenin}

Whilst Block et al. (2013) showed that activation of the Wnt/ß-catenin signalling pathway suppressed DUX4 transcription [125], Banerji et al. (2014) identified $\beta$-catenin as the "main coordinator of FSHD-associated protein interaction signalling" [126]. Pathways encompassing HIF1- $\alpha$ (see "DUX4 downstream signalling: HIF1- $\alpha$ "), tumor necrosis factor (TNF)- $\alpha$ and $c$-Jun N-terminal kinases (JNK) were shown to be clearly disturbed [126] by $\beta$-catenin. The latter are involved in oxidative stress-induced cell death (see "DUX4 Downstream Signalling: ROS"), revealing that $\beta$-catenin is highly influencing DUX4-mediated toxicity. According to Lim et al. (2020), "this consequently results in a negative feedback loop wherein DUX4 activates $\mathrm{Wnt} / \beta$-catenin signalling, which represses its own expression." This may be the reason for the low amount of detectable $D U X 4$ nuclei in FSHD muscle cells [80].

\section{dsRNA, RNASEL and EIF2AK2}

Shadle et al. (2017) found that DUX4 expression increased nuclear double-stranded RNA (dsRNA) accumulation. This can trigger a signalling cascade that inhibits translation and induces apoptosis. The appearance of dsRNAs activates expression of RNASEL and EIF2AK2, which are effectors of the innate immune response particularly against viral invasion by either cleaving intruding RNAs or inhibiting translation [82].

\section{P53 vs. BMP2}

While Wallace et al. (2011) suggested that DUX4-induced cell death relies on the $p 53$ pathway [127], other study findings doubt that $p 53$ is a direct consequence of $D U X 4$ expression [128]. Interestingly, DUX4 overexpression in vitro showed Cyclin Dependent Kinase Inhibitor $1 A$ (CDKN1A) expression, a major $p 53$ target, which codes for $p 21$. However, studies that observed this did not show upregulation of $p 53[129,130]$, but knockdown of $C D K N 1 A$ was shown to enhance the proliferative capacity of DUX4-transfected cells. In this context, it could be shown in vivo that DUX4-induces binding of specificity protein 1 (sp1) to $p 21$ promoter [129]. According to Xu et al. (2014) DUX4 may activate CDKN1A expression through the bone morphogenetic protein (BMP)-2 signalling pathway, which is an upstream actor of $S p 1$. According to the authors, $B M P 2$ mRNA increased after enforced $D U X 4$ expression and was accompanied with an increase of $S p 1$ and $p 21$.

Apart from this, $p 53$ might be triggered by other events as it is reported to correlate with Reactive Oxygen Species (ROS) by acting either as an antioxidant or a prooxidant regulating redox homeostasis. $p 53$ is described to either reduce ROS levels or to induce cell cycle arrest, senescence, and apoptosis [131].

\section{MYC}

DUX4 upregulates $M Y C$, which functions in cell cycle progression and as a mediator of extrinsic and intrinsic pathways of apoptosis. DUX4 overexpression enhances $M Y C$-mediated cell death by stabilizing MYC mRNA [82].

\section{Estrogen}

Teveroni et al. (2017) suggested that the reason why females tend to be less severely affected by FSHD than males is due to estrogens counteracting the differentiation impairment of FSHD myoblasts by estrogen receptor $\beta(E R \beta)$. While they observed an enhanced recruitment of $D U X 4$ transcription factor in the nucleus during muscle differentiation, $E R \beta$ intervened against this recruitment by returning DUX4 into the cytoplasm [132]. However, according to recent clinical findings, differences in endogenous estrogen exposure during life did not appear to have a clinically relevant modifying impact on disease severity in female patients. It suggests that additional sexrelated aspects might also play a role in the further protection from DUX4-induced muscle damage [133].

\section{B2-AR}

Prior to the discovery of $\beta 2$-adrenergic receptor ( $\beta 2$-AR)-agonists influencing FSHD pathogenesis, several trials with $\beta 2$-AR like clenbuterol or salbutamol had been conducted due to their anabolic effects [134-136]. Although they were tried as anabolic agents, they appear to have a direct effect on a DUX4-induced mechanism. While further trials in FSHD patients with salbutamol have shown no major impact as a routine 


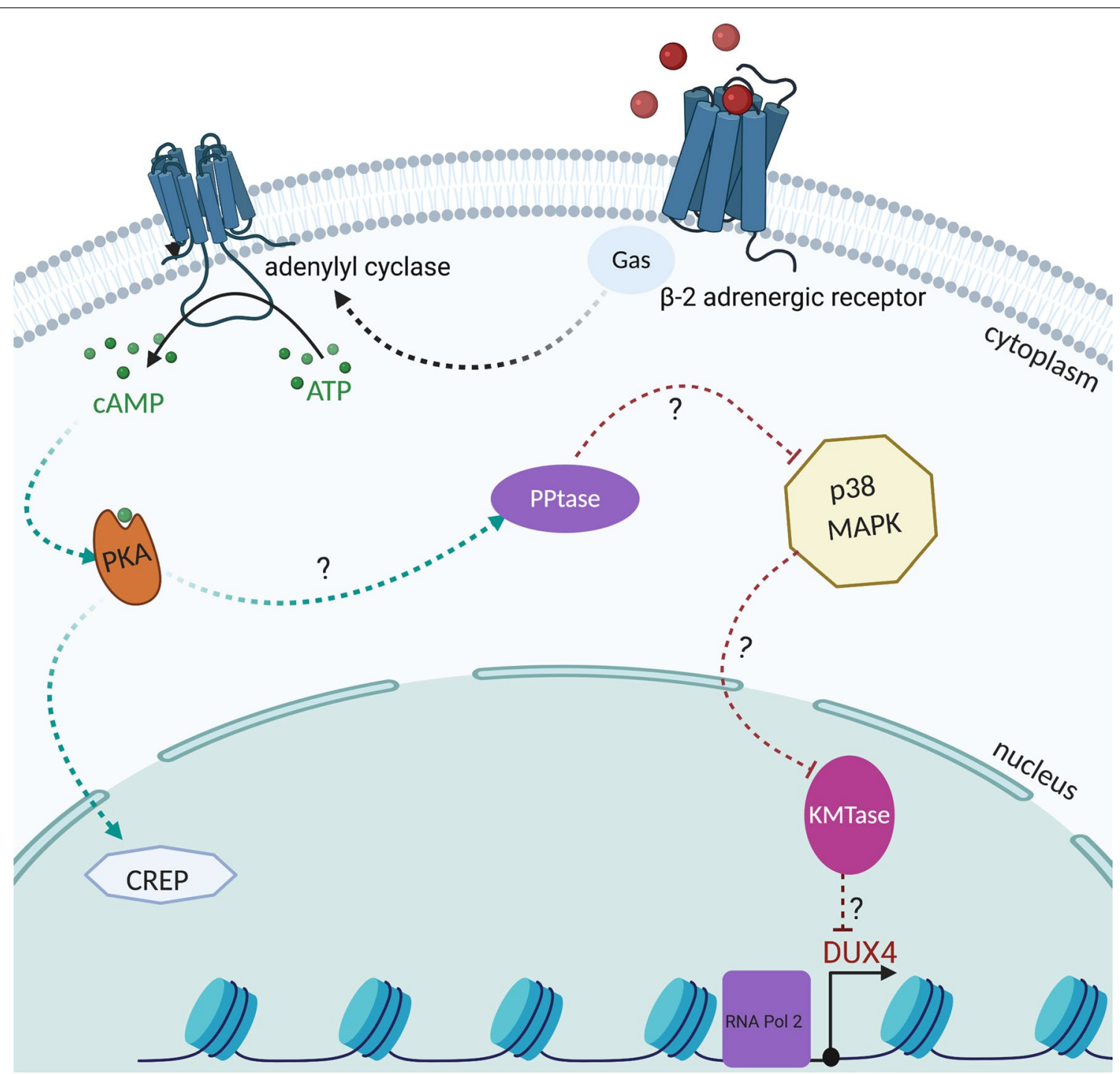

Fig. 7 Model of DUX4 regulation by $\beta-2$ adrenergic signalling. $\beta-2 A R$ binding of agonists induces $G$ protein-mediated activation of adenylyl cyclase, which subsequently catalyzes the formation of CAMP. Downstream effectors of CAMP are PKA-dependent and PKA-independent pathways. $\beta-2$ agonist-mediated inhibition effects on DUX4 expression are likely mediated through PKA-independent pathways acting through signalling molecules such as phosphatases (PPtases) and MAPKs to effect chromatin modifiers, e.g. lysine methyltransferases (KMTases), to influence transcription of the DUX4 gene [140]

treatment for FSHD [18, 137-139], investigations on $\beta 2$-AR have revealed an involvement in the regulation of the D4Z4 array in somatic cells [140]. The participation of molecules and the interconnection between different pathways is still not fully understood [141]. $\beta 2$-AR-agonists increase cAMP levels via adenylate cyclase stimulation through trimeric Gs proteins (see Fig. 7). Efforts to further explore this signalling pathway led to the identification of p38 mitogen activated protein kinase (MAPK) as a major regulator of DUX4 expression. In vitro experiments demonstrated that clinically advanced $\mathrm{p} 38 \alpha$ or $\mathrm{p} 38 \beta$ inhibitors are able to suppress DUX4 expression in FSHD myoblasts and differentiating myocytes. This demonstrated that each of these kinase isoforms plays a different role in activating $D U X 4$. It was shown that p38 inhibitors successfully suppressed DUX4 expression in a mouse xenograft model of human FSHD gene regulation (see "Therapeutic approaches") [34, 141]. 


\section{MRF}

DUX4 expressed at high levels causes rapid cell death, but at low levels it interferes with master myogenic transcription factors-predominantly with $M y o D$. The latter is part of the myogenic regulatory factor (MRF) family, which also comprises the muscle specific proteins Myf5, myogenin (MyoG), and MRF4 (Myf6) [122, 142]. (Several reviews and textbooks regarding the different steps of myogenesis are available.) Whilst $M y f 5$ mRNA was shown to be upregulated by DUX4 possibly representing a compensatory mechanism, Knopp et al. (2016), who analyzed transgenic mice carrying a human D4Z4 genomic locus from an FSHD-affected individual, showed that DUX4 inhibits both MyoD and MyoG gene expression to produce a differentiation defect that cannot be controlled by upregulation of Myf5. DUX4 and its transcriptional activity can be discovered in differentiating human myoblasts [32, 78, 143-145]. There is a "maintenance of a stem-cell-like and less-differentiated state" [143] due to DUX4 expression.

\section{Atrogin 1 and MuRF1}

DUX4 induces the expression of the muscle-specific E3 ubiquitin ligases Atrogin1 (MAFbx) and MuRF1. The ubiquitin proteasome pathway plays a major role in regulating protein degradation and muscle atrophy [146, 147]. Lagirand-Cantaloube et al. (2009) further showed that Atrogin1 suppresses $M y o D$ specific transcriptional activity among the muscle fibre [148].

\section{PAX7}

Whilst $P A X 3$ influences early skeletal muscle formation in the embryo, $P A X 7$ dominates during post-natal growth and muscle regeneration in adult individuals [149]. In FSHD skeletal muscle $P A X 7$ target genes are globally repressed [150]. The paired-homeobox transcription factor stimulates proliferation whilst inhibiting differentiation [151], thus regulating the expansion of satellite cells during myogenesis $[149,152]$. Studies in mice showed that PAX7 could prevent DUX4-mediated toxicity in a dose-dependent way and re-establish myogenic gene expression [130]. While Bosnakovski et al. (2017) suggested some type of competitive interaction [122], Haynes et al. (2017) observed that nuclei do not express both $D U X 4$ and $P A X 7$ proteins and that the transcription factors may not compete for the same genomic binding sites [153]. Remarkably, "DUX4 and PAX7 homeodomains show $100 \%$ identity in their DNA-binding amino acids" [80]. PAX7 target gene repression is a significant biomarker as it correlates with disease severity independently of DUX4 [154].

\section{UPF1}

The evolutionarily conserved protein Up-frameshift protein 1 (UPF1) is one of the main effectors of nonsensemediated mRNA decay (NMD) [155]. Feng et al. (2015) reported that DUX4 stimulates the degradation of UPF1, inducing global accumulation of RNAs, usually degraded as NMD substrates [156]. Interestingly, DUX4 mRNA itself is degraded by NMD. Therefore, "inhibition of NMD by DUX4 protein stabilizes DUX4 mRNA through a double-negative feedback loop in FSHD muscle." [157]

\section{CRYM}

Vanderplanck et al. (2011) showed that DUX4 induces CRYM ( $\mu$-Crystallin) by direct promoter activation. The thyroid-hormone binding protein with nicotinamide adenine dinucleotide phosphate (NADPH)-dependent activity influences differentiation and oxidative stress responses [146, 158]. The physiologic function in skeletal muscle remains to be elucidated. Interestingly, it is additionally expressed in the cochlea and vestibule of the inner ear [159], potentially explaining the occurrence of retinal abnormalities [160] and high-frequency hearing loss [161] in some FSHD patients with severe phenotype.

\section{PITX1}

The paired-like homeodomain transcription factor 1, which encodes a transcription factor that is the "master switch for hindlimb development in embryogenesis" [35], is particularly triggered in FSHD muscles as compared to 11 neuromuscular disorders [7]. It has been discussed as direct DUX4 target gene $[78,127]$. However, according to Zhang et al. (2016) it does not interact physically or functionally with the PITX1 promoter sequence as there is no optimal CT motif [77] (see "DUX4 Protein"). PITX1 has been suggested to explain the asymmetric involvement of FSHD muscles due to its role in creating left-right asymmetry [80]. It is still not well understood how PITX1 contributes to FSHD pathogenesis [7] apart from causing atrophy in adult skeletal muscles and its involvement in inflammation.

\section{H3.X and H3.Y}

Resnick et al. (2019) showed that DUX4 induces expression of the histone variants H3.X and H3.Y. Following a brief pulse of $D U X 4$, these histones incorporate into genes transcriptionally induced by $D U X 4$ and contribute to higher persistence and to improved reactivation of DUX4 target gene expression [162].

\section{P300}

Svensson et al. (2020) demonstrated a general requirement for $p 300$ including CREB-binding protein $(C B P)$ in skeletal muscle contractile function, transcriptional 
homeostasis, and organism survival [163]. DUX4 protein also interacts with the transcriptional coactivator $p 300$ and utilizes its acetyltransferase activity to induce expression of many of its target genes [34, 75, 164].

\section{ROS}

Several indices for the accumulation of ROS in FSHD muscle have been reported. For example, Dimitriev et al. (2016) showed constitutive DNA damage in cultured myoblasts from FSHD, which could be diminished by addition of an antioxidant [121]. Furthermore, several markers for increased oxidative stress, including 4-hydroxynonenal-modified proteins, protein carbonylation, and a lower glutathion (GSH)/ glutathione disulfide (GSSG) ratio have been found in FSHD muscle biopsies [165]. Importantly, DUX4 was shown to reduce the expression of several glutathione redox pathway-associated genes-including phospholipid hydroperoxide glutathione peroxidase (GPX4), glutathione S-transferase A4 (GSTA4) and glutathione S-transferase omega-1 (GSTO1)-in a DUX4-inducible myoblast in vitro model [130]. In muscle biopsies of FSHD patients, however, higher levels of glutathione S-transferase, superoxide dismutase (SOD), catalase, and glutathione reductase have been found-contradicting the aforementioned in vitro results $[165,166]$. In this regard, $p 53$ and its performance as an antioxidant or pro-oxidant under different stress levels could be taken into account. Whereas the antioxidant function of $p 53$ is particularly attained via upregulating the typical antioxidant enzymes, the procedures by which $p 53$ increases ROS are less understood (see "DUX4 Downstream Signalling: P53 vs. BMP2") [131]. Apart from this, it is currently hypothesised, that increased expression of antioxidant defence system proteins is a result of compensatory mechanisms, activated by prolonged and increased oxidative stress [167]. The exact origin of increased ROS, however, still remains unclear. Mitochondrial dysfunction is currently discussed as major source for increased ROS, resulting from decreased oxygen storage capacity [167]. However, muscle cells from FSHD patients are generally acknowledged to have an increased susceptibility to oxidative stress, also emphasizing that mechanisms generating small amounts of ROS should be taken into consideration [165-168]. Increased lactate concentrations, for example, are known to induce low amounts of ROS [169]. Under physiological conditions, this low increase in ROS results in an increased antioxidant defence system or can induce erythroid differentiation [170, 171]. In FSHD muscle, an increase of lactate is evident, as an increased expression of lactate dehydrogenase has been observed in vitro and in vivo $[172,173]$. In line, lower levels of myoglobin and higher activity of HIF1- $\alpha$ strongly indicate a lower oxygen storage capacity in combination with increased anaerobic production of lactate [126, 172, 174, 175]. Therefore, higher basal ROS levels may be partially caused by increased lactate levels. However, this hypothesis awaits further confirmation by future studies. Also, it should be noted that the release of interleukin (IL)-6, a central mediator of inflammation, can be induced by ROS [176, 177]. Therefore, the extensive inflammation reported in FSHD muscle could be induced by an initial increase in $\operatorname{ROS}[167,178]$. As several types of immune cells are known to produce ROS at the site of inflammation, this may result-in combination with the perturbed antioxidative defence system in myocytes-in a chronic inflammation that is held constant via a paracrine mechanism. This may further result in a fatal loop [121] as increased ROS was also identified as the central mediator in the formation of atrophic myotubes.

\section{HIF1-a}

Lek et al. (2020) conducted an unbiased screen utilizing a genome-wide CRISPR-Cas9 loss-of-function library in order to detect possible targets that influence DUX4mediated cell death. Focus was set on genes, in which loss-of-function contributed to survival of muscle cells when DUX4 was expressed. A pathogenic association to the cellular hypoxia response was shown. This was found to be the main driver of $D U X 4$-induced cell death. Under hypoxic conditions, hypoxia-inducible factor 1 (HIF1)- $\alpha$ is stabilized and transfers into the nucleus. It dimerizes with $A R N T$ and shapes the HIF transcription factor. $H I F$ s - in combination with the coactivators $C B P$ and p300-mediate transcription of hypoxia response genes and CDKN1A (one of its target genes). This combination is reported to mediate hypoxia-related growth arrest [179].

\section{Animal models}

The D4Z4 macrosatellite encoding the DUX4 retrogene is "specific to old world primates" [180, 181]. This negates the possibility of working with a "natural" model of the disease in commonly used laboratory animal species. Modelling FSHD in non-primate species that do not express endogenous DUX4 raises concerns of whether the same downstream gene targets and regulatory networks exist, and can be activated as a consequence of DUX4 misexpression to cause disease as in primates [180].

In cultured human FSHD muscle cells there are bursts of DUX4 expression from only a minority of myonuclei [162]. Moreover, protein has not been found directly in patient biopsies. Approaches to model DUX4 myopathy in mice have proven to be too cytotoxic, resulting in embryonic lethality, or in lacking 
muscle phenotypes [182]. The majority of current laboratory animal models of FSHD try to mimic DUX4 misexpression via the transgenic insertion or injection of DUX4. An example of this would be FLExDUX4which is a line of conditional floxed DUX4-FL transgenic mice-that was developed by Jones and Jones (2018) in order to overcome "developmental toxicity of low DUX4 expression from leaky transgenes" and create the conditions for DUX4 animal experiments on mice that are viable and fertile (see: "Therapeutic approaches: AOs") [120]. Also, other promising mouse models have been introduced, such as the doxycyclineinducible model iDUX4pA (pa for PAS) of Bosnakovski et al. (2017) - which makes DUX4 expression dependent on its endogenous relatively inefficient PAS [182] or the tamoxifen-inducible (TIC)-DUX4 mouse model of Giesige et al. (2018)-which conditionally expresses DUX4 in muscles after tamoxifen injection [183]. Mueller et al. (2020) developed a promisingly accurate primate analogue model of FSHD by generating a procedure to xenograft immortalized human muscle precursor cells from FSHD patients into immunodeficient mice to create human muscle xenografts. They reported that FSHD cells "mature into well-organized and innervated human muscle fibres with minimal contamination of murine myonuclei" [184]. They were also managed to reconstitute the satellite cell niche within the xenografts. The xenografts are reported to be structurally comparable to intact human skeletal muscle as human myofibers are innervated and associate with human satellite cells [184]. Nevertheless, the host's immune system must not reject tissue or cells from the donor for cross-species transplantation to be successful. X-irradiation is usually used to disrupt the host satellite cell niche for studies that aim to avoid host-derived muscle regeneration, whilst myotoxins or mechanical injury is used to destroy host muscle fibres [185]. Therefore, due to the use of immune-compromised mice, one disadvantage of the procedure would be the lack of information regarding the contribution of the immune system to disease and disease progression [186, 187].

According to Huml et al. (2020) - who compared literature findings regarding several animals with disease phenotype-there is no single, ideal model that can currently be used to wholly represent FSHD [4]. There are published models in mice, zebrafish, and dogseach engineered through a different approach and producing different results [180]. Therefore, it is suggested that stakeholders should give high priority to collaborating to commit resources to developing an all-encompassing model for FSHD-inclusive of most muscle phenotypes-in one animal [4]. It may then be useful to analyse and use comparable parameters within different organisms. Hendrickson et al. (2017) showed that $D U X 4$ and its mouse ortholog, $D U X$, share central roles in cleavage-specific gene expression and a partial overlap of regulated genes. Determination of the extent of similarity in their transcriptional programs might provide more information about the design of mouse models for FSHD [28].

\section{Molecular treatment strategies}

Current molecular treatment strategies are illustrated in Fig. 8 and include modulating DUX4 repressive pathways, or targeting DUX4 mRNA, DUX4 protein, or cellular downstream effects of DUX4 expression.

\section{p38 inhibition}

Efforts to further explore the signalling pathway of $\beta 2$-adrenergic receptor-agonists led to the identification of p38 MAPK as a major regulator of DUX4 expression (see "DUX4 Downstream Signalling: $\beta 2-A R$ ") [34, 141]. The four isoforms of $\mathrm{p} 38(\alpha / \beta / \gamma / \delta)$ are strongly triggered by several types of environmental stress and inflammatory cytokines, including "oxidative stress, UV irradiation, hypoxia, ischemia, $I L-1$, and TNF- $\alpha$ " [188]. P38 $\alpha$ seems to be the main p38 isoform and is part of the inflammatory response, as its elimination in epithelial cells was reported to decrease proinflammatory gene expression [188]. P38 $\alpha$ MAPK is also regarded as a "molecular switch for the activation of myogenic differentiation" [189]. In fact, p38 $\alpha$ binds to-and regulatesmany promoters during myogenesis [190]. While the factors that directly activate $D U X 4$ gene expression are still unknown [140], in vitro experiments demonstrated that clinically advanced $\mathrm{p} 38 \alpha / \beta$ inhibitors are able to reduce DUX4 expression without disrupting muscle differentiation [141]. Observations showed DUX4 expression is exquisitely sensitive to p38 inhibition and requires much less inhibitor than in the case of blocking differentiation. According to Oliva et al. (2019), when xenograft mice had been treated with the p38 inhibitor losmapimod for 14 days, the total number of both human and mouse muscle cells increased compared to nontreated animals. The molecular mechanisms that tie DUX4 expression to p38 activity remain to be elucidated [34]. However, due to these findings, the study "ReDUX4" was initiated by Fulcrum Therapeutics/ USA to assess "the safety and efficacy of losmapimod" in patients with FSHD1 [191]. Recruitment of volunteers for the trial started in August 2019 and enrollment was completed in February 2020. The trial involves 80 patients who are randomly allocated to either placebo or losmapimod [191]. Patients are given $15 \mathrm{mg}$ of losmapimod or placebo twice a day as two 


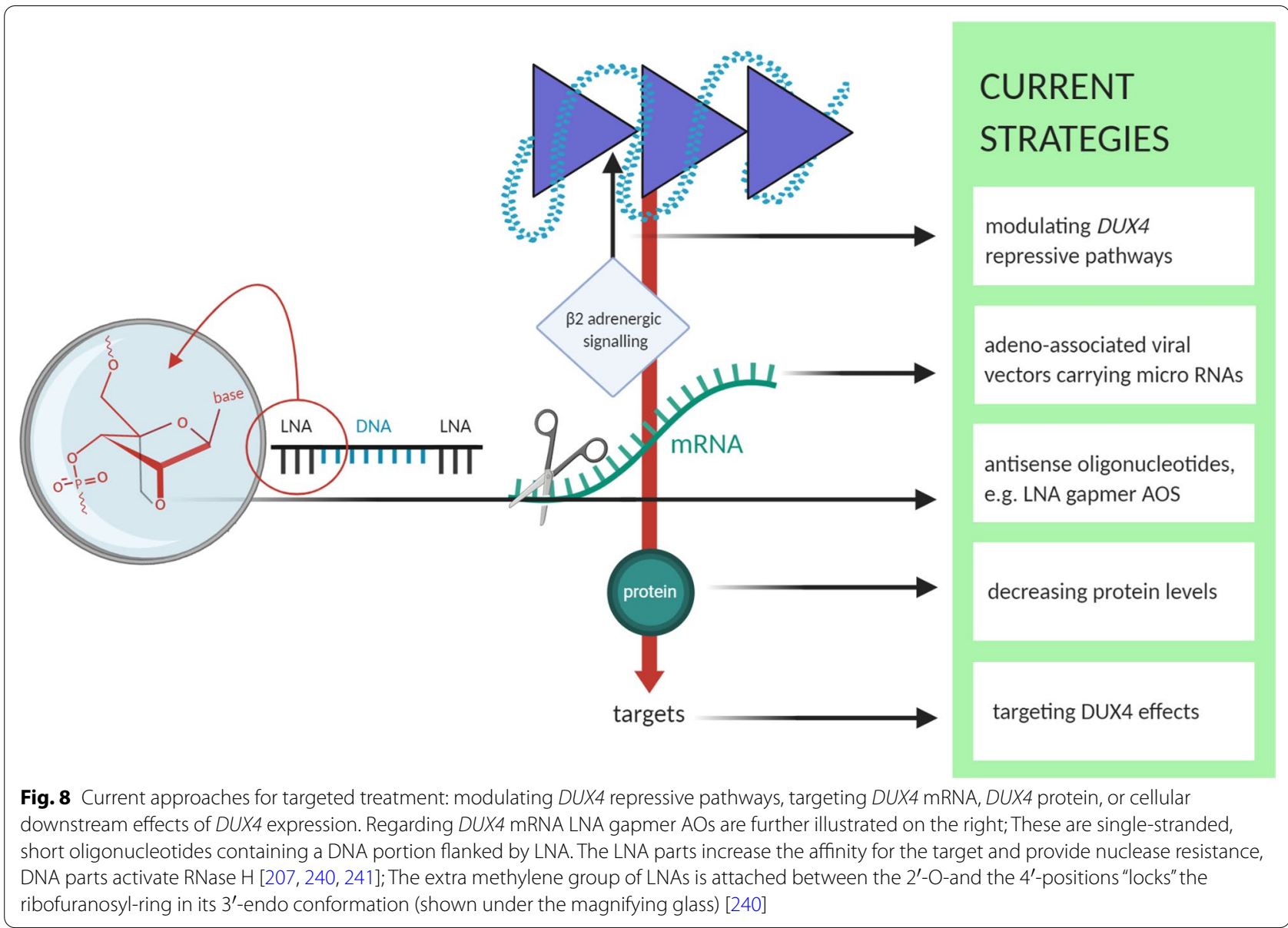

$7.5 \mathrm{mg}$ tablets per oral dose-for a daily total of 4 pills or $30 \mathrm{mg}$ (clinicaltrials.gov: NCT04264442) [192].

It was envisioned that the primary endpoint of the study will be in the first quarter of 2021, and that all data-encompassing all secondary and exploratory endpoints-will be obtained in the second quarter of 2021 . Results from the interim analysis in the first 29 randomized subjects indicate that DUX4-driven gene expression did not show a separation from placebo at 16 weeks. However, muscle biopsies with the highest levels of DUX4 expression before the start of the trial showed a 38-fold reduction in DUX4-driven gene expression following treatment with losmapimod compared to a 5.4-fold reduction with placebo. According to Fulcrum Therapeutics the results indicate that muscle biopsies within the higher levels of DUX4-driven gene expression may be needed to observe a reduction from baseline [193].

\section{miRNAs and AOs}

Whilst vector-based approaches for RNA interference (RNAi) therapy with miRNAs "have remained largely in the pre-clinical realm", antisense oligonucleotide (AO)based approaches have seen more advancement [194]. AOs and miRNAs share a fundamental principle: they bind target RNA through Watson-Crick base pairing. Whilst AOs are developed as short synthetic single strands, miRNA functions as a duplex which is associated with a so-called RNA-induced silencing complex (RISC). In the latter case, one strand (the passenger strand) disappears and the remaining strand (the guide strand) interacts with RISC to bind complementary RNA. The differences between the two approaches show different strengths and weaknesses regarding drug development $[195,196]$.

\section{miRNAs}

The human organism uses miRNAs for gene silencing by creating small sequences with 19-25 nucleotides that target mRNA, thus inhibiting protein production [197]. miRNAs play an essential role in a large number of biological cellular processes such as development, cell differentiation, cell proliferation, or cell death [198]. Each miRNA can possibly regulate hundreds of different 
mRNAs, suggesting that a significant proportion of eukaryotic genes are regulated by miRNAs [199]. Wallace et al. (2018) recently tried to silence DUX4 with adenoassociated viral vectors "to deliver targeted microRNA expression cassettes" (miDUX4s) [194]. They showed proof of concept for this procedure in mice, and made additional efforts to assess matters of safety associated with miDUX4 overexpression and sequence-related offtarget silencing. They reported improvements in vector design and enhancement of their miDUX4 sequence repertory as well as differential toxicity-providing data to help advance RNAi gene therapy for FSHD [194].

The functionality of miRNAs has been researched extensively, but there remain several difficulties regarding "off-target effects" [200], toxicity [201], and undesirable immune responses [202]. The success of synthetically developed miRNAs highly depends on the availability of a safe and efficient transport system for the synthetically modulated RNA sequence into the cell [203].

\section{AOs}

While there have been promising studies regarding the use of AOs [204-206], there remains a need to more effectively knock down DUX4 expression and screen for AOs against DUX4. Lim et al. (2020) used AO chemistries that directly degrade target mRNA and that do not passively act via mRNA processing interference. They worked with locked nucleic acid (LNA) gapmers to knock down DUX4 pre-mRNA [207, 208]. LNA gapmers consist of a central segment of DNA flanked by short LNA stretches (see Fig. 8 (left)) They bind targets by sequence complementarity, producing a DNA/RNA hybrid that is cleaved by RNase $\mathrm{H}$-which leads to gene knockdown [209]. LNAs are a class of modified RNA-nucleic acid analogous that carry a supplementary methylene bridge. This modification makes them resistant to nucleases and increases affinity to complementary RNA sequences [210]. Apart from sugar modifications, phosphorothioate backbones are used along the entire length of the AOs to provide further nuclease resistance $[207,211]$ when binding to RNA targets. Lim et al. (2020) targeted DUX4 premRNA [207, 208], which is generally processed through post-transcriptional modification such as capping, polyadenylation or splicing before it can leave the cell nucleus as mRNA and is available as a template for translation [212]. Lim et al. (2020) showed in vitro that LNA gapmer AOs successfully knock down DUX4 in immortalized FSHD myoblasts and the FLExDUX4 FSHD mouse model. They chose to mainly target DUX4 exon 3, which is specifically associated with the pathogenic DUX4 transcript (see "DUX4 gene expression"). They also found potential functional benefits of AOs on muscle fusion and structure in vitro. In vivo injection of one LNA reduced DUX4 mRNA expression (by $84 \%$ one day after injection and $70 \%$ after repeating the experiment and collecting muscles seven days post injection). According to the authors, while the designed LNA gapmers could knock down DUX4 expression in skeletal muscle significantly and selectively, effects on muscle structure and function, and an evaluation of the pharmacokinetic properties of LNA gapmers in vivo, remain to be determined with a systemic treatment study $[207,208]$.

\section{CRISPR-Cas 13}

Another prospective treatment for FSHD regarding DNA level was introduced by Rashnonejad et al. (2019), who developed a new Cas13/CRISPR mediated DUX4 mRNA silencing method which does not cleave DNA. The treatment can be accurately directed to a RNA transcript of interest utilizing a sequence-specific guide RNA (gRNA), thereby reducing the risk of permanent DNA damage. The authors targeted distinct parts of DUX4 mRNA and showed their ability to markedly suppress DUX4 and inhibit cell death in vitro and in vivo. According to the authors, "additional in vivo studies are underway" regarding the capabilities of the AAV-delivered CRISPR/Cas13 system [213].

\section{G-quadruplex ligands}

Ciszewski et al. (2020) have detected a number of G-quadruplexes (GQs) by using bioinformatic analysis of the genomic DUX4 locus. These are shaping sequences and their presence was demonstrated "in synthetic oligonucleotiode sequences derived from the enhancer, promoter and transcript of DUX4 through circular dichroism and nuclear magnetic resonance analysis." [214]. The authors subsequently analysed the binding character of berberine, a naturally appearing GQ stabilizing compound, to these structures. An in vitro study in FSHD patient myoblasts was conducted using berberine as a treatment. Interestingly, there was a reduction of DUX4 and its target genes. Additional analysis using a DUX4-mouse model validated the therapeutic impact of berberine on downregulating $D U X 4$ protein expression preventing muscle fibrosis, and hence rescuing muscle function [214].

\section{Inhibition of HA biosynthesis}

DeSimone et al. (2019) hoped to identify molecular pathways that mediate $D U X 4$ toxicity by using the $D U X 4$ inducible human myoblast cell line MB135-DUX4i.

$M B 135-D U X 4 i$ has been demonstrated to have similar molecular disease pathologies such as FSHD myogenic cells. In contrast to FSHD cells, which sporadically 
express $D U X 4$ in only a few nuclei at different times $(1$ in every 200 to 1000 cells [179]), MB135-DUX4i cells can be simultaneously stimulated to induce high-level expression of DUX4. This enables molecular analysis of DUX4 pathologies "under controlled and acute experimental conditions" [215].

The authors used proteomic coimmunoprecipitation (co-IP) assays and found that increased hyaluronic acid (HA) levels correlate with observed and several unobserved cellular pathologies. The latter include disturbance of the usually perinuclear localization of $C 1 Q B P$ (a HA-binding protein) and the mitochondria. It was demonstrated that $D U X 4$ expression supports accumulation of HA in DUX4-expressing cells and that multiple DUX4-induced molecular pathologies are mediated by HA which accumulates following DUX4 induction. DUX4-expressing myoblasts, treated with the competitive HA biosynthesis-inhibitor 4-methylumbelliferone (4MU), inhibited DUX4-mediated accumulation of HA and the initiation of the pathologies without having an observable influence on DUX4 protein amount or nuclear localization. These findings demonstrate HA as an important influencer of $D U X 4$ pathology that operates at an early stage in DUX4 pathogenesis [215].

\section{Inhibition of the cellular hypoxia response}

A pathogenic connection to the cellular hypoxia response-which is the main influencer of DUX4induced cell death (see "DUX4 downstream signalling: HIF1- $\alpha$ ")-was demonstrated by conducting a genomewide CRISPR-Cas9 screen to detect genes whose lossof-function provide survival in case of DUX4 expression. Studies that used the immortalized myoblast line MB135$D U X 4 i$, combined with a doxycycline-inducible DUX4 transgene to guarantee continuous DUX4 expression in all cells, showed that the cellular hypoxia response can be disturbed with inhibitors of the phosphatidylinositol 3-kinase (PI3K)/Akt/mTOR [216] and Ras/mitogen-activated protein kinase (MAPK) signalling pathways [217] (see "Therapeutic approaches: p38 inhibition"-MAPK inhibitors are also used in context of $\beta 2 \mathrm{AR}$ signalling). When treating patient cells, PI3K/Akt/mTOR inhibitors showed more effectiveness at a lower dose and were thus selected for further analysis. Inhibition led to enhanced DUX4 protein turnover and reduction of the cellular hypoxia response and apoptosis. Furthermore, FSHD disease biomarkers could be decreased in patient myogenic lines, whilst structural and functional attributes in two zebrafish models of FSHD could be improved [179].

\section{Current therapy approaches Antioxidants}

Antioxidant treatment of FSHD is considered a reasonable approach given that increased oxidative stress seems to be a central mechanism in this disease. Several reports demonstrate the beneficial effects of antioxidants on FSHD muscles in vitro, including a higher resistance against $\mathrm{H}_{2} \mathrm{O}_{2}$, reduced $D U X 4$-induced toxicity and improved myotube formation [121, 218]. However, results are inconclusive in FSHD patients. Whilst a combinatory treatment with vitamin $\mathrm{C}$, vitamin $\mathrm{E}$, zinc, and selenium improved the maximum voluntary contraction and endurance of quadriceps in FSHD patients, results from a two-minute walk test, were insignificantly different [219]. Contrary to the above results, supplementation of methionine and folic acid (both potent antioxidants [220, 221] could not demonstrate a beneficial effect on muscle health or disease state [222]. Interestingly, a combined supplementation of docosahexaenoic acid, eicosapentaenoic acid, vitamin E, curcumin, acetyl-L-carnitine, vitamin C, coenzyme Q10, dry extract of the roots of scutellaria, and dry extract of green tea, demonstrated significant positive effects on a 6 min walk distance and the isokinetic knee extension in FSHD patients [223]. It should be noted that the sample size was less than 27 subjects per group in all studies, potentially masking any beneficial effect from the corresponding treatment. Therefore, conclusions from antioxidant treatments are unreliable given the low number of studies and small population sizes. Nevertheless, the limited beneficial effects observed provide a rationale to conduct larger multi-centred trials.

\section{Aerobic exercise and strength training}

Five cardiovascular training trials done by 111 FSHD participants proved the positive effects that aerobic exercise training has on patients with FSHD [224]. Muscle mass diminishes $3-8 \%$ per decade after the age of 30 , and decreases at a higher rate after the age of 60 . In this regard, exercise training and appropriate nutrition can have remarkable effects on muscle mass and strength [224-227]. Therefore, in the case of FSHD, exercising regularly is vital as untrained muscles accelerate the aging process and lead to reduced muscular resilience and chronic muscle pain [226]. Also, strength traininginvolving several repetitions with light weights [228]is considered a valid option for FSHD patients. "High Intensity Interval Training " (HIIT) should only be done under medical supervision [226]. Furthermore, training should be combined with physical therapy and adapted to individual needs in order to counteract physical overload [229]. A combination of aerobic exercise and strength training (and cognitive-behavioural therapy) should 
therefore be considered given the benefits that aerobic exercise has demonstrated [224, 230, 231]. In a study by Bankolé et al. (2016), sixteen FSHD patients were randomly split up in training (TG) and control (CG) groups (both $\mathrm{n}=8$ ) in a 6-month home-based training program. (The CG-patients also did an identical exercise intervention after this time period.) The training-schedule consisted of cycling 3 times a week for $35 \mathrm{~min}$. Remarkable improvements could be shown in the peak oxygen uptake and maximal aerobic power by week 6 -up to week 24 . Improvements in muscle endurance, maximal quadriceps strength, and 6-min walking distance was demonstrated. Moreover, fatigue was reported to decrease. "Muscle fibre cross-sectional area and citrate synthase activity increased by $34 \%$ and $46 \%$, respectively." [231]. However, according to Voet et al. (2019), many studies remain insufficient for subgroup analyses (regarding patients with severe or mild phenotype), sample size, duration, or evaluation of dose-response relationships. Additional research with strong methodology and more participants is required [224].

\section{Conclusion}

The aim of this review is to provide an overview of FSHD regarding genetics, pathophysiology, currently discussed therapy approaches, and future aspects of methodology. There remains potential in the role of modifier genes that have not been identified yet, looking at direct D4Z4 binding proteins [140] or gender specific effects of DUX4 signalling [133]. An early intervention of DNA levels in order to minimize $D U X 4$-effects may have the most positive results given that $D U X 4$ is believed to induce hundreds of different target genes [28, 119]. In this context, the locus of the 4q telomere at the nuclear envelope [117] and the long distance interactions of D4Z4 seem to be particularly important in disease progression considering both methylation levels of the 4q35 locus and a changed gene expression $[60,118]$ beyond $D U X 4$ expression.

Also, further research of signalling pathways behind the effect of $\beta 2$ adrenergic receptor-agonists showed that p38 mitogen-activated protein kinase is a mediator of DUX4 expression [34]. Use of LNA gapmer AOs recently lead to the successful inactivation of $D U X 4$ at pre-RNA levels [207, 208].

Investigations into the CRISPR/Cas13 system are currently being conducted [213].

It was found that DUX4 protein uses different systems such as the hyaluronic acid pathway [215] and G-quadruplexes [214] for further action. Although chemical inhibitors have been shown to suppress DUX4 effects, further research is needed to build upon the new findings. Researchers are beginning to use screens of small molecules to discover drugs that influence D4Z4 methylation or translation of $D U X 4$. Regarding $D U X 4$ targets, ROS seem to have an important role in alleviating the effects of DUX4 toxicity in the disease mechanism, whilst current research has linked the main driver of apoptosis to cellular hypoxia response [179]. The growing pace of drug development has generated an urgent requirement for clinical trial readiness [108]. The relevance of clinical trial planning is prominent, and standardization is becoming more necessary. Current therapy approaches try to counteract muscle loss and weakness. In this context, antioxidants combined with aerobic exercise and light strength training are considered to be vital in alleviating DUX4 toxicity [223, 226, 231]. However, in this regard, several studies use small sample sizes whilst specifications regarding the examination criteria remain unclear [224]. Therefore, the international multicentre study ReSolved (March 2018-March 2022) may result in more efficient clinical trial designs [108]. Against this background, further research should focus on disease severity (in relation to age and gender), pre-exercised muscle, lifestyle, affected muscle groups regarding pain, quality of life, and the individual genetics. FSHD is a genetically complex type of muscular dystrophy. Therefore, detailed information about study participants, categories regarding disease severity, and standardization of methodology may significantly help to interpret results.

\section{Outlook}

Patient registries, biomarkers (see "Disease monitoring"), and clinical outcome measures (see "Trial readiness") have to be included in order to facilitate targeted therapy and diagnostics. Disease progression can be adequately monitored by using standardized clinical evaluation such as the Comprehensive Clinical Evaluation Form (CCEF) [232-234] in combination with parameters like the clinical severity score by Ricci et al. ("Ricci score") [233] and the FSHD clinical score [235]. These tools are especially important for the standardization of follow-up-studies. Also, family studies must be conducted in order to elucidate the extent of disease variability.

It is uncertain if methylation analysis is a useful tool for FSHD diagnosis and prognosis given that the factors which influence the methylation status of the D4Z4 macrosatellites are currently not fully understood. In this regard, Nikolic et al. (2020) observed a high variable distribution of D4Z4 methylation whilst investigating D4Z4 methylation status at $4 \mathrm{q} 35$ in a large cohort of patients through methylation-sensitive restriction enzymes 1 (MRSE1)[58]. Therefore, methylation techniques per se are not sufficient. Exactly how the nuclear lamina impacts on global chromatin architecture needs to be further examined. In FSHD, the short D4Z4 array seems to interrupt interaction amonst D4Z4, the telomere, and 
the nuclear periphery (which is usually organized via long distance loops, encompassing 2 ToADs in the context of a higher order chromatin organisation). The altered gene expression in this regard involves genes such as FAT1 and $S O R B S 2$, which should be included in further investigations as both genes have been shown to play a role in skeletal muscle [60, 116, 118].

Stakeholders should prioritize collaboration and commitment of resources in order to develop an allencompassing FSHD model that includes most muscle phenotypes in a single animal [4]. However, attempts to model FSHD in animal models are difficult since the pathophysiological mechanisms of DUX4 expression are not fully understood. No model has yet been able to encompass all the characteristic effects of DUX4 expression regarding differently affected muscle parts, extramuscular manifestations, right-left asymmetry, or gender-specific effects. Therefore, it might be useful to analyse and use comparable parameters within different organisms (see "Animal models"). Neverthlesss, differences in animal models are currently inevitable especially given that FSHD is a disease for which non-primate animal models remain imperfect.

Recently a Cas13/CRISPR mediated DUX4 mRNA silencing method has been developed which targets RNA (not DNA) and can be specifically directed to a RNA transcript of interest utilizing a sequence-specific guide RNA [213]. This, in combination with the strategies illustrated in this review, seems to be a promising approach especially as it makes Cas 13 a potentially significant therapy for influencing gene expression without altering genome sequence. Additional in vivo studies are underway regarding the capabilities of the AAV-delivered CRISPR/Cas13 system. The results of this method may be an exciting field for future investigations.

\footnotetext{
Abbreviations

3D FISH: Three-dimensional fluorescent in situ hybridization; 4MU: 4-Methylumbelliferone; $3^{\prime} U T R$ : Three prime untranslated region; $\beta 2$-AR: $\beta 2$-Adrenergic receptor; ACSL1: Acyl-COA synthetase long chain family member 1; AO: Antisense oligonucleotide; AFO: Ankle-foot orthotic; ARNT: Aryl hydrocarbon receptor nuclear translocator; ATPase: Adenyltriphosphatase; BAMS: Bosma arhinia microphthalmia syndrome; Bmp2: Bone morphogenetic protein 2; CAMP: Cyclic adenosine monophosphate; CBP: CREB-binding protein; CCEF: Comprehensive clinical evaluation form; CDKN1A: Cyclin dependent kinase inhibitor 1A; CG: Control group; ChIP-seq: Chromatin immunoprecipitation DNA-sequencing; $\mathrm{ClS}$ : Checklist individual strength; $\mathrm{CO}_{2}$ : Carbon dioxide; COA: Clinical outcome assessment; Co-IP: Coimmunoprecipitation; CRISPR: Clustered regularly interspaced short palindromic repeats; CRYM: Crystallin $\mu$; CTCF: CCCTC-binding factor; DNMT3B: De novo methyltransferase 3B; dsRNA: Double-stranded RNA; DUX4: Double Homeobox 4; DUX4-FL: DUX4full-lengths; DUX4-S: DUX4-short; EcoRl: Restriction endonuclease I from Escherichia coli; EIF2AK2: Eukaryotic translation initiation factor 2 alpha kinase 2; EIM: Electrical impedance myography; FAT1: FAT atypical cadherin 1; FSHD: Facioscapulohumeral muscular dystrophy; FSHD-COM: FSHD composite outcome measure; GPX4: Phospholipid hydroperoxide glutathione peroxidase; GQ: G-quadruplex; GSH: Glutathion; GSSG: Glutathione disulfide; GSTA4: Glutathione S-transferase A4; GSTO1: Glutathione S-transferase omega-1;
}

$\mathrm{H}_{2} \mathrm{O}_{2}$ : Hydrogen peroxide; $\mathrm{H} 3 \mathrm{~K} 9$ me3: Tri-methylation at the 9th lysine residue of the histone H3 protein; HA: Hyaluronic acid; HIF1A: Hypoxia-inducible factor 1-alpha; HIIT: High intensity interval training; HP1: Heterochromatin protein 1; ICF-syndrome: Immunodeficiency, centromeric instability, and facial anomalies syndrome; L: Interleukin; KAFO: Knee-ankle-foot orthotic; KMTase: Lysine methyltransferase; LAD: Lamin associated domain; LNA: Locked nucleic acid; MAPK: Mitogen activated protein kinase; MB135-DUX4i: DUX4-inducible human myoblast cell line 135; miDUX4s: MicroRNA expression cassettes; miRNA: MicroRNA; MMT: Manual muscle testing; MRF: Myogenic regulatory factors; MRF4: Muscle regulatory factor 4; MRI: Magnetic resonance imaging; mRNA: Messenger RNA; MRSE1: Methylation-sensitive restriction enzymes 1; mTOR: Mammalian target of rapamycin; MuRF1: Muscle RING-finger protein-1; Myf5: Myogenic factor 5; Myf6: Myogenic factor 6; MyoD: Myogenic differentiation 1; MyoG: Myogenin; NADPH: Nicotinamide adenine dinucleotide phosphate; NIV: Non-invasive ventilation; NLS: Nuclear localization signal; NMD: Nonsense-mediated mRNA decay; ORF: Open reading frame; PI3K: Phosphatidylinositol 3-kinase; PAS: Polyadenylation signal; PAX3: Paired Box 3; PAX7: Paired Box 7; PITX1: Paired-like homeodomain transcription factor 1; PKA: Protein kinase A; PPTase: Phosphatase; QMT: Quantitative myometry; Ras: Rat sarcoma; RISC: RNA-induced silencing complex; RNAi: RNA interference; RNase H: Ribonuclease H; RNASEL: Ribonuclease L; ROS: Reactive oxygen species; RT-PCR: Reverse transcription polymerase chain reaction; SMCHD1: Structural maintenance of chromosomes flexible hinge domain containing 1; SNP: Single nucleotide polymorphism; SOD: Superoxide dismutase; SORBS2: Sorbin and SH3 domain-containing protein 2; Sp1: Specificity protein 1; STIR: Signal on short-tau inversion recovery; ToAD: Topologically associating domain; TAD: Transcription-activating domain; TG: Training group; TIC-DUX4 model: Tamoxifen-inducible-DUX4 model; TNF-a: Tumor necrosis factor alpha; UPF1: Up-frameshift protein 1; VNTR: Variable number tandem repeat; WWC2: WW and $C 2$ domain containing 2.

\section{Acknowledgements}

The authors would like to thank Fungisai Matemadombo for constructive criticism of the manuscript.

\section{Authors' contributions}

TS conceived the work and the figures; TS, LK and H-PD wrote the manuscript. All authors read and approved the final manuscript.

\section{Funding}

Open Access funding enabled and organized by Projekt DEAL. This work was supported by a scholarship for Lars Kaiser from the Federal Ministry of Science, Research and Art of Baden-Württemberg; support by Steinbeis Center for Personalized Medicine (StZ1789) is gratefully acknowledged.

\section{Availability of data and materials}

Data sharing is not applicable to this article as no datasets were generated or analysed during the current study.

\section{Declarations}

Ethics approval and consent to participate

Not applicable.

\section{Consent for publication}

Not applicable.

\section{Competing interests}

The authors declare that they have no competing interests.

\section{Author details \\ ${ }^{1}$ Institute of Precision Medicine, Medical and Life Sciences Faculty, Furtwan- gen University, Jakob-Kienzle-Straße 17, 78054 Villingen-Schwenningen, Germany. ${ }^{2}$ Institute of Pharmaceutical Sciences, University of Freiburg, Albert- straße 25, 79104 Freiburg i. Br., Germany. ${ }^{3}$ EXIM Department, Fraunhofer Institute IZI, Leipzig, Schillingallee 68, 18057 Rostock, Germany. ${ }^{4}$ Faculty of Sci- ence, Tuebingen University, Auf der Morgenstelle 8, 72076 Tübingen, Germany.}

Received: 13 October 2020 Accepted: 25 February 2021

Published online: 12 March 2021 


\section{References}

1. facio therapies. Living with FSHD. https://www.facio-therapies.com/ living-with-fshd/. 2020.

2. Dib C, Saada YB, Dmitriev P, Richon C, Dessen P, Laoudj-Chenivesse D, Carnac G, Lipinski M, Vassetzky YS. Correction of the FSHD myoblast differentiation defect by fusion with healthy myoblasts. J Cell Physiol. 2016:231:62-71.

3. Saad N, Pyne N, Copeland J, Harper S. Engineering more efficient therapeutic miRNAs for FSHD gene therapy. Mol Ther. 2020;28:1-592.

4. Huml RA, Uspenskaya-Cadoz O, Dawson J, Slifer Z. Updating the clinical picture of facioscapulohumeral muscular dystrophy: ramifications for drug development with potential solutions. Ther Innov Regul Sci. 2020:54:144-50.

5. Tawil R, Kissel JT, Heatwole C, Pandya S, Gronseth G, Benatar M. Evidence-based guideline summary: evaluation, diagnosis, and management of facioscapulohumeral muscular dystrophy. Neurology. 2015;85:357-64

6. Goselink RJM, Mul K, Van Kernebeek CR, et al. Early onset as a marker for disease severity in facioscapulohumeral muscular dystrophy. Neurology. 2019;92:E378-85.

7. Pandey SN, Cabotage J, Shi R, Dixit M, Sutherland M, Liu J, Muger S, Harper SQ, Nagaraju K, Chen YW. Conditional over-expression of PITX1 causes skeletal muscle dystrophy in mice. Biol Open. 2012;1:629-39

8. Chen TH, Wu YZ, Tseng YH. Early-onset infantile facioscapulohumeral muscular dystrophy: a timely review. Int J Mol Sci. 2020;21:1-17.

9. Hamel J, Tawil R. Facioscapulohumeral muscular dystrophy: update on pathogenesis and future treatments. Neurotherapeutics. 2018;15:863-71.

10. Jordan B, Müller-Reible C, Zierz S. Fazioskapulohumerale Muskeldystrophie. Klinik Atypien Diagnostik Genetik Nervenarzt. 2011;82:712-22.

11. Greco A, Goossens R, van Engelen B, van der Maarel SM. Consequences of epigenetic derepression in facioscapulohumeral muscular dystrophy. Clin Genet. 2020. https://doi.org/10.1111/cge.13726.

12. Henke C, Spiesshoefer J, Kabitz HJ, Herkenrath S, Randerath W, Brix T, Görlich D, Young P, Boentert M. Respiratory muscle weakness in facioscapulohumeral muscular dystrophy. Muscle Nerve. 2019;60:679-86.

13. Scully MA, Eichinger KJ, Donlin-Smith CM, Tawil R, Statland JM. Restrictive lung involvement in facioscapulohumeral muscular dystrophy. Muscle Nerve. 2014;50:739-43.

14. Attarian S, Salort-Campana E, Nguyen K, Behin A, Andoni Urtizberea $J$. Recommendations for the management of facioscapulohumeral muscular dystrophy in 2011. Rev Neurol (Paris). 2012;168:910-8.

15. Pastorello E, Cao M, Trevisan CP. Atypical onset in a series of 122 cases with facioscapulohumeral muscular dystrophy. Clin Neurol Neurosurg. 2012;114:230-4

16. Ricci G, Scionti I, Sera F, et al. Large scale genotype-phenotype analyses indicate that novel prognostic tools are required for families with facioscapulohumeral muscular dystrophy. Brain. 2013;136:3408-17.

17. Hamel J, Johnson N, Tawil R, Martens WB, Dilek N, McDermott MP, Heatwole C. Patient-reported symptoms in facioscapulohumeral muscular dystrophy (PRISM-FSHD). Neurology. 2019;93:E1180-92.

18. Van Der Kooi EL, Kalkman JS, Lindeman E, Hendriks JCM, Van Engelen BGM, Bleijenberg G, Padberg GW. Effects of training and albuterol on pain and fatigue in facioscapulohumeral muscular dystrophy. J Neurol. 2007;254:931-40

19. Schipper K, Bakker M, Abma T. Fatigue in facioscapulohumeral muscular dystrophy: a qualitative study of people's experiences. Disabil Rehabil. 2017:39:1840-6.

20. Morís G, Wood L, FernáNdez-Torrón R, et al. Chronic pain has a strong impact on quality of life in facioscapulohumeral muscular dystrophy. Muscle Nerve. 2018;57:380-7.

21. Association MD. Exercising with a muscle disease. Quest 1-34. 2009

22. Goselink RJ, Voermans NC, Okkersen K, et al. Early onset facioscapulohumeral dystrophy - a systematic review using individual patient data. Neuromuscul Disord. 2017;27:1077-83.

23. Brouwer OF, Padberg GW, Bakker E, Wijmenga C, Frants RR. Early onset facioscapulohumeral muscular dystrophy. Muscle Nerve Suppl. 1995; 18:S67-72
24. Klinge L, Eagle M, Haggerty ID, Roberts CE, Straub V, Bushby KM. Severe phenotype in infantile facioscapulohumeral muscular dystrophy. Neuromuscul Disord. 2006:16:553-8.

25. Chen $\mathrm{TH}$, Lai $\mathrm{YH}$, Lee $\mathrm{PL}$, et al. Infantile facioscapulohumeral muscular dystrophy revisited: expansion of clinical phenotypes in patients with a very short EcoRl fragment. Neuromuscul Disord. 2013;23:298-305.

26. Lemmers RJLF, Van Der VPJ, Klooster R, et al. A unifying genetic model for facioscapulohumeral muscular dystrophy. Science (80-). 2010:329:1650-3.

27. Wijmenga C, Hewitt JE, Sandkuijl LA, et al. Chromosome 4q DNA rearrangements associated with facioscapulohumeral muscular dystrophy. Nat Genet. 1992;2:26-30.

28. Hendrickson PG, Doráis JA, Grow EJ, et al. Conserved roles of mouse DUX and human DUX4 in activating cleavage-stage genes and MERVL/ HERVL retrotransposons. Nat Genet. 2017;49:925-34.

29. Whiddon JL, Langford AT, Wong CJ, Zhong JW, Tapscott SJ. Conservation and innovation in the DUX4-family gene network. Nat Genet. 2017:49:935-40.

30. De laco A, Planet E, Coluccio A, Verp S, Duc J, Trono D. DUX-family transcription factors regulate zygotic genome activation in placental mammals. Nat Genet. 2017;49:941-5.

31. Hewitt JE. Loss of epigenetic silencing of the DUX4 transcription factor gene in facioscapulohumeral muscular dystrophy. Hum Mol Genet. 2015:24:R17-23.

32. Snider L, Geng LN, Lemmers RJLF, et al. Facioscapulohumeral dystrophy: incomplete suppression of a retrotransposed gene. PLOS Genet. 2010;6:1-14.

33. Das S, Chadwick BP. Influence of repressive histone and DNA methylation upon D4Z4 transcription in non-myogenic cells. PLoS ONE. 2016;11:1-26

34. Oliva J, Galasinski S, Richey A, Campbell AE, Meyers MJ, Modi N, Zhong JW, Tawil R, Tapscott SJ, Sverdrup FM. Clinically advanced p38 inhibitors suppress DUX4 expression in cellular and animal models of facioscapulohumeral muscular dystrophys. J Pharmacol Exp Ther. 2019:370:219-30.

35. Richards M, Coppée F, Thomas N, Belayew A, Upadhyaya M. Facioscapulohumeral muscular dystrophy (FSHD): an enigma unravelled? Hum Genet. 2012;131:325-40.

36. Lemmers RJLF, Wohlgemuth M, Van Der Gaag KJ, Van Der Vliet PJ, Van Teijlingen CMM, De Knijff P, Padberg GW, Frants RR, Van Der Maarel SM. Specific sequence variations within the $4 \mathrm{q} 35$ region are associated with facioscapulohumeral muscular dystrophy. Am J Hum Genet. 2007;81:884-94.

37. Lemmers RJLF, van der Vliet PJ, van der Gaag KJ, Zuniga S, Frants RR, de Knijff $P$, van der Maarel SM. Worldwide population analysis of the $4 q$ and $10 q$ subtelomeres identifies only four discrete interchromosomal sequence transfers in human evolution. Am J Hum Genet. 2010;86:364-77.

38. van Deutekom JC, Bakker E, Lemmers RJ, van der Wielen MJ, Bik E, Hofker MH, Padberg GW, Frants RR. Evidence for subtelomeric exchange of $3.3 \mathrm{~kb}$ tandemly repeated units between chromosomes 4q35 and 10q26: implications for genetic counselling and etiology of FSHD1. Hum Mol Genet. 1996;5:1997-2003.

39. Marsollier A-C, Joubert R, Mariot V, Dumonceaux J. Targeting the polyadenylation signal of pre-mRNA: a new gene silencing approach for facioscapulohumeral dystrophy. Int J Mol Sci. 2018;19:1347.

40. de Greef JC, Wohlgemuth M, Chan OA, Hansson KB, Smeets D, Frants RR, Weemaes CM, Padberg GW, van der Maarel SM. Hypomethylation is restricted to the D4Z4 repeat array in phenotypic FSHD. Neurology. 2007:69:1018-26.

41. Goossens R, Van Den Boogaard ML, Lemmers RJLF, et al. Intronic SMCHD1 variants in FSHD: Testing the potential for CRISPR-Cas9 genome editing. J Med Genet. 2019;56:828-37.

42. Sacconi S, Briand-Suleau A, Gros M, et al. FSHD1 and FSHD2 form a disease continuum. Neurology. 2019;92(19):e2273-85. https://doi. org/10.1212/WNL.0000000000007456.

43. Lemmers RJ, Van Der Vliet PJ, Balog J, et al. Deep characterization of a common D4Z4 variant identifies biallelic DUX4 expression as a modifier for disease penetrance in FSHD2. Eur J Hum Genet. 2018;26:94-106.

44. Nguyen K, Broucqsault N, Chaix C, et al. Deciphering the complexity of the $4 q$ and $10 q$ subtelomeres by molecular combing in healthy 
individuals and patients with facioscapulohumeral dystrophy. J Med Genet. 2019;56:590-601.

45. Lemmers RJLF, Tawil R, Petek LM, et al. Digenic inheritance of an SMCHD1 mutation and an FSHD-permissive D4Z4 allele causes facioscapulohumeral muscular dystrophy type 2. Nat Genet. 2012;44:1370-4.

46. van den Boogaard ML, Lemmers RJLF, Balog J, et al. Mutations in DNMT3B modify epigenetic repression of the D4Z4 repeat and the penetrance of facioscapulohumeral dystrophy. Am J Hum Genet. 2016;98:1020-9.

47. Hamanaka K, Šikrová D, Mitsuhashi S, et al. Homozygous nonsense variant in LRIF1 associated with facioscapulohumeral muscular dystrophy. Neurology. 2020;94:e2441-7.

48. Salsi V, Magdinier F, Tupler R. Does DNA methylation matter in FSHD? Genes (Basel). 2020. https://doi.org/10.3390/genes11030258.

49. Statland JM, Donlin-Smith CM, Tapscott SJ, Lemmers RJLF, Van Der Maarel SM, Tawil R. Milder phenotype in facioscapulohumeral dystrophy with 7-10 residual D4Z4 repeats. Neurology. 2015;85:2147-50.

50. Ricci G, Zatz M, Tupler R. Facioscapulohumeral muscular dystrophy: more complex than it appears. Curr Mol Med. 2014;14:1052-68.

51. Jones $\mathrm{TI}$, King $\mathrm{OD}$, Himeda $\mathrm{CL}$, et al. Individual epigenetic status of the pathogenic D4Z4 macrosatellite correlates with disease in facioscapulohumeral muscular dystrophy. Clin Epigenetics. 2015;7:1-22.

52. Lemmers RJLF, Goeman JJ, van der Vliet PJ, et al. Inter-individual differences in CpG methylation at D4Z4 correlate with clinical variability in FSHD1 and FSHD2. Hum Mol Genet. 2015;24:659-69.

53. Gaillard M-C, Roche S, Dion C, et al. Differential DNA methylation of the D4Z4 repeat in patients with FSHD and asymptomatic carriers. Neurology. 2014;83:733-42.

54. Zeng W, de Greef JC, Chen Y-Y, et al. Specific loss of histone H3 lysine 9 trimethylation and $\mathrm{HP} 1 \gamma /$ cohesin binding at D4Z4 repeats is associated with facioscapulohumeral dystrophy (FSHD). PLOS Genet. 2009:5:e1000559.

55. Larsen M, Rost S, El Hajj N, Ferbert A, Deschauer M, Walter MC, Schoser B, Tacik P, Kress W, Müller CR. Diagnostic approach for FSHD revisited: SMCHD1 mutations cause FSHD2 and act as modifiers of disease severity in FSHD1. Eur J Hum Genet. 2015;23:808-16.

56. Himeda $\mathrm{CL}$, Jones PL. The genetics and epigenetics of facioscapulohumeral muscular dystrophy. Annu Rev Genomics Hum Genet. 2019;20:265-91.

57. Calandra P, Cascino I, Lemmers RJLF, et al. Allele-specific DNA hypomethylation characterises FSHD1 and FSHD2. J Med Genet. 2016;53:348-55

58. Nikolic A, Jones TI, Govi M, et al. Interpretation of the epigenetic signature of facioscapulohumeral muscular dystrophy in light of genotypephenotype studies. Int J Mol Sci. 2020. https://doi.org/10.3390/ijms2 1072635.

59. Dion C, Roche S, Laberthonnière C, et al. SMCHD1 is involved in de novo methylation of the DUX4-encoding D4Z4 macrosatellite. Nucleic Acids Res. 2019;47:2822-39.

60. Gaillard MC, Broucqsault N, Morere J, Laberthonnière C, Dion C, Badja C, Roche S, Nguyen K, Magdinier F, Robin JD. Analysis of the 4q35 chromatin organization reveals distinct long-range interactions in patients affected with facio-scapulo-humeral dystrophy. Sci Rep. 2019;9:1-15.

61. Zheng X, Hu J, Yue S, Kristiani L, Kim M, Sauria M, Taylor J, Kim Y, Zheng Y. Lamins organize the global three-dimensional genome from the nuclear periphery. Mol Cell. 2018;71:802-15.

62. Ulianov SV, Doronin SA, Khrameeva EE, et al. Nuclear lamina integrity is required for proper spatial organization of chromatin in Drosophila. Nat Commun. 2019;10:1-11.

63. Robin JD, Magdinier F. Chapter 6-higher-order chromatin organization in diseases: from chromosomal position effect to phenotype variegation. In: Tollefsbol TO, editor. Handbook of epigenetics. 2nd ed. London: Academic Press; 2017. p. 73-92.

64. van Overveld PGM, Lemmers RJFL, Sandkuijl LA, Enthoven L, Winokur ST, Bakels F, Padberg GW, van Ommen G-JB, Frants RR, van der Maarel SM. Hypomethylation of D4Z4 in 4q-linked and non-4q-linked facioscapulohumeral muscular dystrophy. Nat Genet. 2003;35:315-7.

65. Shaw ND, Brand H, Kupchinsky ZA, et al. SMCHD1 mutations associated with a rare muscular dystrophy can also cause isolated arhinia and Bosma arhinia microphthalmia syndrome. Nat Genet. 2017;49:238-48.
66. Gordon CT, Xue S, Yigit G, et al. De novo mutations in SMCHD1 cause Bosma arhinia microphthalmia syndrome and abrogate nasal development. Nat Genet. 2017:49:249-55.

67. Coker H, Brockdorff N. SMCHD1 accumulates at DNA damage sites and facilitates the repair of DNA double-strand breaks. J Cell Sci. 2014;127:1869-74.

68. Wilkie AOM. Many faces of SMCHD1. Nat Genet. 2017:49:176-8.

69. Campbell AE, Belleville AE, Resnick R, Shadle SC, Tapscott SJ. Facioscapulohumeral dystrophy: activating an early embryonic transcriptional program in human skeletal muscle. Hum Mol Genet. 2018;27:R153-62.

70. van den Boogaard ML, Thijssen PE, Aytekin C, et al. Expanding the mutation spectrum in ICF syndrome: evidence for a gender bias in ICF2. Clin Genet. 2017:92:380-7.

71. Lemmers RJLF, Van Der SN, Van Der VPJ, Moore SA, Mozaffar T, Kimonis $\checkmark$, Selvatici R, Ferlini A. SMCHD1 mutation spectrum for facioscapulohumeral muscular dystrophy type 2 (FSHD2) and Bosma arhinia microphthalmia syndrome (BAMS) reveals disease-specific localisation of variants in the ATPase domain. J Med Genet. 2019;56:693-700.

72. Tassin A, Laoudj-Chenivesse D, Vanderplanck C, Barro M, Charron S, Ansseau E, Chen YW, Mercier J, Coppée F, Belayew A. DUX4 expression in FSHD muscle cells: how could such a rare protein cause a myopathy? J Cell Mol Med. 2013;17:76-89.

73. Geng LN, Yao Z, Snider L, et al. DUX4 activates germline genes, retroelements, and immune mediators: implications for facioscapulohumeral dystrophy. Dev Cell. 2012;22:38-51.

74. Mitsuhashi H, Ishimaru S, Homma S, Yu B, Honma Y, Lou BM, Miller JB. Functional domains of the FSHD-associated DUX4 protein. Biol Open. 2018. https://doi.org/10.1242/bio.033977.

75. Klingler C, Ashley J, Shi K, Stiefvater A, Kyba M, Sinnreich M, Aihara H, Kinter J. DNA aptamers against the DUX4 protein reveal novel therapeutic implications for FSHD. FASEB J. 2020;34:4573-90.

76. Bosnakovski D, Shams AS, Yuan C, et al. Transcriptional and cytopathological hallmarks of FSHD in chronic DUX4-expressing mice. J Clin Invest. 2020;130:2465-77.

77. Zhang Y, Lee JK, Toso EA, Lee JS, Choi SH, Slattery M, Aihara H, Kyba M. DNA-binding sequence specificity of DUX4. Skelet Muscle. 2016;6:1-11.

78. Dixit M, Ansseau E, Tassin A, et al. DUX4, a candidate gene of facioscapulohumeral muscular dystrophy, encodes a transcriptional activator of PITX1. Proc Natl Acad Sci U S A. 2007;104:18157-62.

79. Svan der Maarel SM, Tawil R, Tapscott SJ. Facioscapulohumeral muscular dystrophy and DUX4: breaking the silence. Trends Mol Med. 2012:17:252-8.

80. Lim KRQ, Nguyen Q, Yokota T. Review. DUX4 signalling in the pathogenesis of facioscapulohumeral muscular dystrophy. Int J Mol Sci. 2020;21:729.

81. Yao Z, Snider L, Balog J, Lemmers RJLF, Van Der Maarel SM, Tawil R, Tapscott SJ. DUX4-induced gene expression is the major molecular signature in FSHD skeletal muscle. Hum Mol Genet. 2014;23:5342-52.

82. Shadle SC, Zhong JW, Campbell AE, Conerly ML, Jagannathan S, Wong CJ, Morello TD, van der Maarel SM, Tapscott SJ. DUX4-induced dsRNA and MYC mRNA stabilization activate apoptotic pathways in human cell models of facioscapulohumeral dystrophy. PLoS Genet. 2017;13:1-25.

83. Mariot $\mathrm{V}$, Roche $\mathrm{S}$, Hourdé $\mathrm{C}$, et al. Correlation between low FAT1 expression and early affected muscle in facioscapulohumeral muscular dystrophy. Ann Neurol. 2015;78:387-400.

84. Lemmers RJLF, O'Shea S, Padberg GW, Lunt PW, van der Maarel SM. Best practice guidelines on genetic diagnostics of Facioscapulohumeral muscular dystrophy: Workshop 9th June 2010, LUMC, Leiden, The Netherlands. Neuromuscul Disord. 2012;22:463-70.

85. Bakker E, Wijmenga C, Vossen RH, Padberg GW, Hewitt J, van der Wielen M, Rasmussen K, Frants RR. The FSHD-linked locus D4F104S1 (p13E-11) on 4q35 has a homologue on 10qter. Muscle Nerve Suppl. 1995;2:S39-44.

86. Deidda G, Cacurri S, Piazzo N, Felicetti L. Direct detection of 4q35 rearrangements implicated in facioscapulohumeral muscular dystrophy (FSHD). J Med Genet. 1996:33:361-5.

87. Cacurri S, Piazzo N, Deidda G, Vigneti E, Galluzzi G, Colantoni L, Merico B, Ricci E, Felicetti L. Sequence homology between 4qter and 10qter loci facilitates the instability of subtelomeric Kpnl repeat units implicated in facioscapulohumeral muscular dystrophy. Am J Hum Genet. 1998;63:181-90. 
88. Matsumura T, Goto K, Yamanaka G, Lee JH, Zhang C, Hayashi YK, Arahata K. Chromosome 4q;10q translocations; comparison with different ethnic populations and FSHD patients. BMC Neurol. 2002. https://doi. org/10.1186/1471-2377-2-7.

89. Zheng $Y$, Kong L, Xu H, et al. Rapid prenatal diagnosis of facioscapulohumeral muscular dystrophy 1 by combined Bionano optical mapping and karyomapping. Prenat Diagn. 2020;40:317-23.

90. Vielhaber S, Jakubiczka S, Schröder JM, Sailer M, Feistner H, Heinze $\mathrm{H}-\mathrm{J}$, Wieacker P, Bettecken T. Facioscapulohumeral muscular dystrophy with EcoRl/BInl fragment size of more than $32 \mathrm{~kb}$. Muscle Nerve. 2002;25:540-8.

91. Upadhyaya M, Maynard J, Rogers MT, Lunt PW, Jardine P, Ravine D, Harper PS. Improved molecular diagnosis of facioscapulohumeral muscular dystrophy (FSHD): validation of the differential double digestion for FSHD. J Med Genet. 1997;34:476-9.

92. Fisher J, Upadhyaya M. Molecular genetics of facioscapulohumeral muscular dystrophy (FSHD). Neuromuscul Disord. 1997;7:55-62.

93. Butz M, Koch MC, Müller-Felber W, Lemmers RJLF, Van Der Maarel SM, Schreiber H. Facioscapulohumeral muscular dystrophy: phenotypegenotype correlation in patients with borderline D4Z4 repeat numbers. J Neurol. 2003;250:932-7.

94. Vasale J, Boyar F, Jocson M, et al. Molecular combing compared to Southern blot for measuring D4Z4 contractions in FSHD. Neuromuscul Disord. 2015;25:945-51.

95. Van Der Maarel SM, Deidda G, Lemmers RJLF, et al. De novo facioscapulohumeral muscular dystrophy: frequent somatic mosaicism, sex-dependent phenotype, and the role of mitotic transchromosomal repeat interaction between chromosomes 4 and 10. Am J Hum Genet. 2000;66:26-35.

96. Tamhankar P, Phadke S. Clinical profile and molecular diagnosis in patients of facioscapulohumeral dystrophy from Indian subcontinent. Neurol India. 2010;58:436-40.

97. Preston MK, Tawil R, Wang LH. Facioscapulohumeral muscular dystrophy. In: Adam M, Ardinger H, Pagon R (eds) GeneReviews ${ }^{\circledR}$. University of Washington, Seattle; 1993-2020. 1999. pp 1-23

98. Dai Y, Li P, Wang Z, et al. Single-molecule optical mapping enables quantitative measurement of D4Z4 repeats in facioscapulohumeral muscular dystrophy (FSHD). bioRxiv 1-27. 2018.

99. Nguyen K, Puppo F, Roche S, et al. Molecular combing reveals complex 4q35 rearrangements in facioscapulohumeral dystrophy. Hum Mutat. 2017;38:1432-41.

100. Nguyen $K$, Walrafen $P$, Bernard $R$, et al. Molecular combing reveals allelic combinations in facioscapulohumeral dystrophy. Ann Neurol. 2011;70:627-33.

101. Wang N, Wu Z, Wang C, Wang Z, Lin M, Fang L, Murong S. Mechanism of translocation between chromosomes $4 \mathrm{q}$ and $10 \mathrm{q}$ in facioscapulohumeral muscular dystrophy. Zhonghua Yi Xue Za Zhi. 2003;83:650-3.

102. Chapman K, Dragan K. Hypercarbia. StatPearls. 2020.

103. Moreira S, Wood L, Smith D, et al. Respiratory involvement in ambulant and non-ambulant patients with facioscapulohumeral muscular dystrophy. J Neurol. 2017;264:1271-80

104. Tawil R, Mah JK, Baker S, et al. Clinical practice considerations in facioscapulohumeral muscular dystrophy Sydney, Australia, 21 September 2015. Neuromuscul Disord. 2016;26:462-71.

105. FSH Society. About FSHD. 1-24. 2015.

106. Statland JM, Sacconi S, Farmakidis C, Donlin-Smith CM, Chung M, Tawil R. Coats syndrome in facioscapulohumeral dystrophy type 1: frequency and D4Z4 contraction size. Neurology. 2013;80:1247-50.

107. Monforte M, Laschena F, Ottaviani P, Bagnato MR, Pichiecchio A, Tasca G, Ricci E. Tracking muscle wasting and disease activity in facioscapulohumeral muscular dystrophy by qualitative longitudinal imaging. J Cachexia Sarcopenia Muscle. 2019;10:1258-65.

108. Lorusso S, Johnson NE, McDermott MP, et al. Clinical trial readiness to solve barriers to drug development in FSHD (ReSolve): protocol of a large, international, multi-center prospective study. BMC Neurol. 2019:19:1-13.

109. Statland JM, Heatwole C, Eichinger K, Dilek N, Martens WB, Tawil R. Electrical impedance myography in facioscapulohumeral muscular dystrophy. Muscle Nerve. 2016;54:696-701.

110. Mul K, Heatwole C, Eichinger K, Dilek N, Martens WB, Van EBGM, Tawil R, Statland JM, City K. Electrical impedance myography in facioscapulohumeral muscular dystrophy: a one year follow-up study. Muscle Nerve. 2018;58:213-8.

111. Rutkove SB, Caress JB, Cartwright MS, et al. Electrical impedance myography as a biomarker to assess ALS progression. Amyotroph Lateral Scler. 2012;13:439-45.

112. Zaidman CM, Wang LL, Connolly AM, et al. Electrical impedance myography in duchenne muscular dystrophy and healthy controls: a multicenter study of reliability and validity. Muscle Nerve. 2015;52:592-7.

113. Rutkove SB, Shefner JM, Gregas M, Butler H, Caracciolo J, Lin C, Fogerson PM, Mongiovi P, Darras BT. Characterizing spinal muscular atrophy with electrical impedance myography. Muscle Nerve. 2010;42:915-21.

114. $\mathrm{NIH}$. Clinical trial readiness to solve barriers to drug development in FSHD. In: ClinicalTrials.gov. 2019.

115. Eichinger $\mathrm{K}$, Heatwole $\mathrm{C}$, lyadurai $\mathrm{S}$, et al. Facioscapulohumeral muscular dystrophy functional composite outcome measure. Muscle Nerve. 2018. https://doi.org/10.1002/mus.26088.

116. Caruso N, Herberth B, Bartoli M, et al. Deregulation of the protocadherin gene FAT1 alters muscle shapes: implications for the pathogenesis of facioscapulohumeral dystrophy. PLOS Genet. 2013;9:e1003550.

117. Masny PS, Bengtsson U, Chung SA, Martin JH, van Engelen B, van der Maarel SM, Winokur ST. Localization of 4q35.2 to the nuclear periphery: is FSHD a nuclear envelope disease? Hum Mol Genet. 2004;13:1857-71.

118. Robin JD, Ludlow AT, Batten K, Gaillard MC, Stadler G, Magdinier F, Wright WE, Shay JW. SORBS2 transcription is activated by telomere position effect-over long distance upon telomere shortening in muscle cells from patients with facioscapulohumeral dystrophy. Genome Res. 2015;25:1781-90.

119. Ferreboeuf M, Mariot V, Bessières B, et al. DUX4 and DUX4 downstream target genes are expressed in fetal FSHD muscles. Hum Mol Genet. 2014:23:171-81.

120. Jones T, Jones PL. A cre-inducible DUX4 transgenic mouse model for investigating facioscapulohumeral muscular dystrophy. PLoS ONE. 2018. https://doi.org/10.1371/journal.pone.0192657.

121. Dmitriev P, Bou Saada Y, Dib C, et al. DUX4-induced constitutive DNA damage and oxidative stress contribute to aberrant differentiation of myoblasts from FSHD patients. Free Radic Biol Med. 2016;99:244-58.

122. Bosnakovski D, Toso E, Hartweck L, Magli A, Lee H, Thompson E, Dandapat A, Perlingeiro R, Kyba M. The DUX4 homeodomains mediate inhibition of myogenesis and are functionally exchangeable with the Pax7 homeodomain. J Cell Sci. 2017;130:3685-97.

123. Statland JM, Shah B, Henderson D, van der Maarel S, Tapscott SJ, Tawil R. Muscle pathology grade for facioscapulohumeral muscular dystrophy biopsies. Muscle Nerve. 2015;52:521-6.

124. Janssen BH, Voet NBM, Nabuurs $\mathrm{Cl}$, Kan HE, De Rooy JWJ, Geurts AC, Padberg GW, Van Engelen BGM, Heerschap A. Distinct disease phases in muscles of facioscapulohumeral dystrophy patients identified by MR detected fat infiltration. PLoS ONE. 2014;9:1-9.

125. Block GJ, Narayanan D, Amell AM, Petek LM, Davidson KC, Bird TD, Tawil R, Moon RT, Miller DG. Wnt/ $\beta$-catenin signaling suppresses DUX4 expression and prevents apoptosis of FSHD muscle cells. Hum Mol Genet. 2013;22:4661-72.

126. Banerii CRS, Knopp P, Moyle LA, Severini S, Orrell RW, Teschendorff $A E$, Zammit PS. $\beta$-catenin is central to DUX4-driven network rewiring in facioscapulohumeral muscular dystrophy. J R Soc Interface. 2015. https://doi.org/10.1098/rsif.2014.0797.

127. Wallace LM, Garwick SE, Mei W, Belayew A, Coppee F, Ladner KJ, Guttridge D, Yang J, Harper SQ. DUX4, a candidate gene for facioscapulohumeral muscular dystrophy, causes p53-dependent myopathy in vivo. Ann Neurol. 2011;69:540-52.

128. Bosnakovski D, Gearhart MD, Toso EA, Recht OO, Cucak A, Jain AK, Barton MC, Kyba M. p53-independent DUX4 pathology in cell and animal models of facioscapulohumeral muscular dystrophy. Dis Model Mech. 2017:10:1211-6.

129. Xu H, Wang Z, Jin S, Hao H, Zheng L, Zhou B, Zhang W, Lv H, Yuan Y. Dux4 induces cell cycle arrest at G1 phase through upregulation of p21 expression. Biochem Biophys Res Commun. 2014;446:235-40.

130. Bosnakovski D, Xu Z, Ji Gang E, et al. An isogenetic myoblast expression screen identifies DUX4-mediated FSHD-associated molecular pathologies. EMBO J. 2008;27:2766-79. 
131. Chen Y, Liu K, Shi Y, Shao C. The tango of ROS and p53 in tissue stem cells. Cell Death Differ. 2018;25:637-9.

132. Teveroni E, Pellegrino M, Sacconi S, et al. Estrogens enhance myoblast differentiation in facioscapulohumeral muscular dystrophy by antagonizing DUX4 activity. J Clin Invest. 2017;127:1531-45.

133. Mul K, Horlings CGC, Voermans NC, Schreuder THA, van Engelen BGM. Lifetime endogenous estrogen exposure and disease severity in female patients with facioscapulohumeral muscular dystrophy. Neuromuscul Disord. 2018;28:508-11.

134. Moore NG, Pegg GG, Sillence MN. Anabolic effects of the beta 2-adrenoceptor agonist salmeterol are dependent on route of administration. Am J Physiol Metab. 1994;267:E475-84.

135. Hostrup M, Reitelseder S, Jessen S, et al. Beta2-adrenoceptor agonist salbutamol increases protein turnover rates and alters signalling in skeletal muscle after resistance exercise in young men. J Physiol. 2018;596:4121-39.

136. Le Panse B, Arlettaz A, Portier H, Lecoq AM, De Ceaurriz J, Collomp K. Short term salbutamol ingestion and supramaximal exercise in healthy women. Br J Sports Med. 2006:40:627-31.

137. Payan CA, Hogrel JY, Hammouda EH, et al. Periodic salbutamol in facioscapulohumeral muscular dystrophy: a randomized controlled trial. Arch Phys Med Rehabil. 2009;90:1094-101.

138. Kissel JT, McDermott MP, Mendell JR, King WM, Pandya S, Griggs RC, Tawil R. Randomized, double-blind, placebo-controlled trial of albuterol in facioscapulohumeral dystrophy. Neurology. 2001;57:1434-40.

139. Van Der Kooi EL, Vogels OJM, Van Asseldonk RJGP, Lindeman E, Hendriks JCM, Wohlgemuth M, Van Der Maarel SM, Padberg GW. Strength training and albuterol in facioscapulohumeral muscular dystrophy. Neurology. 2004;63:702-8.

140. Campbell AE, Oliva J, Yates MP, et al. BET bromodomain inhibitors and agonists of the beta-2 adrenergic receptor identified in screens for compounds that inhibit DUX4 expression in FSHD muscle cells. Skelet Muscle. 2017:7:1-18.

141. Rojas $L A$, Valentine $E$, Accorsi $A$, et al. p38a regulates expression of DUX4 in a model of facioscapulohumeral muscular dystrophys. J Pharmacol Exp Ther. 2020;374:489-98.

142. Bosnakovski D, Gearhart MD, Toso EA, Ener ET, Choi SH, Kyba M. Low level DUX4 expression disrupts myogenesis through deregulation of myogenic gene expression. Sci Rep. 2018. https://doi.org/10.1038/ s41598-018-35150-8.

143. Knopp P, Krom YD, Banerji CRS, Panamarova M, Moyle LA, den Hamer $B$, van der Maarel SM, Zammit PS. DUX4 induces a transcriptome more characteristic of a less-differentiated cell state and inhibits myogenesis. J Cell Sci. 2016;129:3816-31.

144. Jones TI, Chen JCJ, Rahimov F, et al. Facioscapulohumeral muscular dystrophy family studies of DUX4 expression: evidence for disease modifiers and a quantitative model of pathogenesis. Hum Mol Genet. 2012;21:4419-30

145. Rickard AM, Petek LM, Miller DG. Endogenous DUX4 expression in FSHD myotubes is sufficient to cause cell death and disrupts RNA splicing and cell migration pathways. Hum Mol Genet. 2015;24:5901-14.

146. Vanderplanck C, Ansseau E, Charron S, Stricwant N, Tassin A, LaoudjChenivesse D, Wilton SD, Coppée F, Belayew A. The FSHD atrophic myotube phenotype is caused by DUX4 expression. PLoS ONE. 2011. https://doi.org/10.1371/journal.pone.0026820.

147. Gumucio JP, Mendias CL. Atrogin-1, MuRF-1, and sarcopenia. Endocrine. 2013:43:12-21.

148. Lagirand-Cantaloube J, Cornille K, Csibi A, Batonnet-Pinchon S, Leibovitch MP, Leibovitch SA. Inhibition of atrogin-1/MAFbx mediated MyoD proteolysis prevents skeletal muscle atrophy in vivo. PLoS ONE. 2009. https://doi.org/10.1371/journal.pone.0004973.

149. Buckingham M, Relaix F. PAX3 and PAX7 as upstream regulators of myogenesis. Semin Cell Dev Biol. 2015;44:115-25.

150. Banerji CRS, Panamarova M, Hebaishi H, White RB, Relaix F, Severini S, Zammit PS. PAX7 target genes are globally repressed in facioscapulohumeral muscular dystrophy skeletal muscle. Nat Commun. 2017. https ://doi.org/10.1038/s41467-017-01200-4.

151. Addicks GC, Brun CE, Sincennes MC, Saber J, Porter CJ, Francis Stewart A, Ernst P, Rudnicki MA. MLL1 is required for PAX7 expression and satellite cell self-renewal in mice. Nat Commun. 2019. https://doi. org/10.1038/s41467-019-12086-9.
152. Von Maltzahn J, Jones AE, Parks RJ, Rudnicki MA. Pax7 is critical for the normal function of satellite cells in adult skeletal muscle. Proc Natl Acad Sci U S A. 2013:110:16474-9.

153. Haynes P, Kernan K, Zhou SL, Miller DG. Expression patterns of FSHDcausing DUX4 and myogenic transcription factors PAX3 and PAX7 are spatially distinct in differentiating human stem cell cultures. Skelet Muscle. 2017;7:1-13.

154. Banerji CRS, Zammit PS. PAX7 target gene repression is a superior FSHD biomarker than DUX4 target gene activation, associating with pathological severity and identifying FSHD at the single-cell level. Hum Mol Genet. 2019;28:2224-36.

155. Imamachi N, Tani H, Akimitsu N. Up-frameshift protein 1 (UPF1): multitalented entertainer in RNA decay. Drug Discov Ther. 2012;6:55-61.

156. Fiorini F, Bagchi D, Le Hir H, Croquette V. Human Upf1 is a highly processive RNA helicase and translocase with RNP remodelling activities. Nat Commun. 2015. https://doi.org/10.1038/ncomms8581.

157. Feng Q, Snider L, Jagannathan S, Tawil R, van der Maarel SM, Tapscott SJ, Bradley RK. A feedback loop between nonsense-mediated decay and the retrogene DUX4 in facioscapulohumeral muscular dystrophy. Elife. 2015;2015:1-13.

158. Klimov E. Facioscapulohumeral muscular dystrophy: the molecular signaling pathway. J Neurol Stroke. 2017:6:14-6.

159. Oshima A, Suzuki S, Takumi Y, Hashizume K, Abe S, Usami S. CRYM mutations cause deafness through thyroid hormone binding properties in the fibrocytes of the cochlea. J Med Genet. 2006;43:2-5.

160. Goselink RJM, Schreur V, van Kernebeek CR, Padberg GW, van der Maarel SM, van Engelen BGM, Erasmus CE, Theelen T. Ophthalmological findings in facioscapulohumeral dystrophy. Brain Commun. 2019;1:1-9.

161. Lutz KL, Holte L, Kliethermes SA, Stephan C, Mathews KD. Clinical and genetic features of hearing loss in facioscapulohumeral muscular dystrophy. Neurology. 2013;81:1374-7.

162. Resnick R, Wong CJ, Hamm DC, Bennett SR, Skene PJ, Hake SB, Henikoff S, van der Maarel SM, Tapscott SJ. DUX4-induced histone variants H3.X and H3.Y Mark DUX4 target genes for expression. Cell Rep. 2019:29:1812-1820.e5.

163. Svensson K, LaBarge SA, Sathe A, et al. p300 and CAMP response element-binding protein-binding protein in skeletal muscle homeostasis, contractile function, and survival. J Cachexia Sarcopenia Muscle. 2020;11:464-77.

164. Choi SH, Gearhart MD, Cui Z, Bosnakovski D, Kim M, Schennum N, Kyba M. DUX4 recruits $\mathrm{p300/CBP}$ through its C-terminus and induces global H3K27 acetylation changes. Nucleic Acids Res. 2016;44:5161-73.

165. Turki A, Hayot M, Carnac G, et al. Functional muscle impairment in facioscapulohumeral muscular dystrophy is correlated with oxidative stress and mitochondrial dysfunction. Free Radic Biol Med. 2012;53:1068-79.

166. Laoudj-Chenivesse D, Carnac G, Bisbal C, Hugon G, Bouillot S, Desnuelle C, Vassetzky Y, Fernandez A. Increased levels of adenine nucleotide translocator 1 protein and response to oxidative stress are early events in facioscapulohumeral muscular dystrophy muscle. J Mol Med. 2005;83:216-24.

167. Denny AP, Heather AK. Are antioxidants a potential therapy for FSHD? A review of the literature. Oxid Med Cell Longev. 2017. https://doi. org/10.1155/2017/7020295

168. Choi MH, Ow JR, Di YN, Taneja R. Oxidative stress-mediated skeletal muscle degeneration: molecules, mechanisms, and therapies. Oxid Med Cell Longev. 2016. https://doi.org/10.1155/2016/6842568.

169. Hashimoto T, Hussien R, Oommen S, Gohil K, Brooks GA. Lactate sensitive transcription factor network in L6 cells: activation of MCT1 and mitochondrial biogenesis. FASEB J. 2007;21:2602-12.

170. Tauffenberger A, Fiumelli H, Almustafa S, Magistretti PJ. Lactate and pyruvate promote oxidative stress resistance through hormetic ROS signaling. Cell Death Dis. 2019;10:1-16.

171. Luo ST, Zhang DM, Qin Q, et al. The promotion of erythropoiesis via the regulation of reactive oxygen species by lactic acid. Sci Rep. 2017;7:38105

172. Winokur ST, Chen YW, Masny PS, Martin JH, Ehmsen JT, Tapscott SJ, van der Maarel SM, Hayashi Y, Flanigan KM. Expression profiling of FSHD muscle supports a defect in specific stages of myogenic differentiation. Hum Mol Genet. 2003;12:2895-907. 
173. Kowaljow V, Marcowycz A, Ansseau E, et al. The DUX4 gene at the FSHD1A locus encodes a pro-apoptotic protein. Neuromuscul Disord. 2007; 17:611-23.

174. Tsumagari K, Chang SC, Lacey M, Baribault C, Chittur SV, Sowden J, Tawil R, Crawford GE, Ehrlich M. Gene expression during normal and FSHD myogenesis. BMC Med Genomics. 2011;4:67

175. Olivier N, Boissière J, Allart E, Mucci P, Thevenon A, Daussin F, Tiffreau $\checkmark$. Evaluation of muscle oxygenation by near infrared spectroscopy in patients with facioscapulohumeral muscular dystrophy. Neuromuscul Disord. 2016;26:47-55

176. Tanaka T, Narazaki M, Kishimoto T. II-6 in inflammation, immunity, and disease. Cold Spring Harb Perspect Biol. 2014;6:16295-6.

177. Zhao Y, Usatyuk PV, Gorshkova IA, et al. Regulation of COX-2 expression and IL-6 release by particulate matter in airway epithelial cells. Am J Respir Cell Mol Biol. 2009;40:19-30.

178. Choi J-H, Park Y-E, Shin J-H, Lee C-H, Kim D-S. Extensive inflammatory reaction in facioscapulohumeral muscular dystrophy. Ann Clin Neurophysiol. 2017;19:141.

179. Lek A, Zhang Y, Woodman KG, et al. Applying genome-wide CRISPRCas9 screens for therapeutic discovery in facioscapulohumeral muscular dystrophy. Sci Transl Med. 2020. https://doi.org/10.1126/scitranslm ed.aay0271.

180. Lek A, Rahimov F, Jones PL, Kunkel LM. Emerging preclinical animal models for FSHD. Trends Mol Med. 2016:21:295-306.

181. Leidenroth A, Hewitt JE. A family history of DUX4: phylogenetic analysis of DUXA, B, C and Duxbl reveals the ancestral DUX gene. BMC Evol Biol. 2010;10:364.

182. Bosnakovski D, Chan SSK, Recht OO, Hartweck LM, Gustafson CJ, Athman LL, Lowe DA, Kyba M. Muscle pathology from stochastic low leve DUX4 expression in an FSHD mouse model. Nat Commun. 2017;8:550

183. Giesige $C R$, Wallace $L M$, Heller KN, et al. AAV-mediated follistatin gene therapy improves functional outcomes in the TIC-DUX4 mouse mode of FSHD. JCl insight. 2018. https://doi.org/10.1172/jci.insight.123538.

184. Mueller AL, O'Neill A, Jones TI, et al. Muscle xenografts reproduce key molecular features of facioscapulohumeral muscular dystrophy. Exp Neurol. 2019. https://doi.org/10.1016/j.expneurol.2019.113011.

185. Mueller AL, Bloch RJ. Skeletal muscle cell transplantation: models and methods. J Muscle Res Cell Motil. 2019. https://doi.org/10.1007/s1097 4-019-09550-w.

186. Tidball JG. Mechanisms of muscle injury, repair, and regeneration. Compr Physiol. 2011;1(4):2029-62. https://doi.org/10.1002/cphy.c1000 92.

187. Yang W, Hu P. Skeletal muscle regeneration is modulated by inflammation. J Orthop Transl. 2018;13:25-32.

188. Cargnello M, Roux PP. Activation and function of the MAPKs and their substrates, the MAPK-activated protein kinases. Microbiol Mol Biol Rev. 2011;75:50-83.

189. Li YP, Niu A, Wen Y. Regulation of myogenic activation of $p 38$ MAPK by TACE-mediated TNFa release. Front Cell Dev Biol. 2014;2:1-5.

190. Segalés J, Perdiguero E, Muñoz-Cánoves P. Regulation of muscle stem cell functions: A focus on the p38 MAPK signaling pathway. Front Cell Dev Biol. 2016;4:1-15.

191. FSHD Society. ReDUX4 clinical trial update. 2020

192. National Library of Medicine. Efficacy and safety of losmapimod in subjects with facioscapulohumeral muscular dystrophy (FSHD). In: ClinicalTrials.gov. 2020

193. Fulcrum Therapeutics. Fulcrum therapeutics announces interim analysis data from its ReDUX4 trial in facioscapulohumeral muscular dystrophy (FSHD). 2020

194. Wallace LM, Saad NY, Pyne NK, et al. Pre-clinical safety and off-target studies to support translation of AAV-mediated RNAi therapy for FSHD. Mol Ther Methods Clin Dev. 2018;8:121-30.

195. Watts J, Corey D. Gene silencing by siRNAs and antisense oligonucleotides in the laboratory and the clinic. J Pathol. 2012:226:365-79.

196. Ha M, Kim VN. Regulation of microRNA biogenesis. Nat Rev Mol Cell Biol. 2014:15:509-24.

197. Lam JKW, Chow MYT, Zhang Y, Leung SWS. siRNA versus miRNA as therapeutics for gene silencing. Mol Ther Nucleic Acids. 2015;4:e252.

198. Bueno MJ, Malumbres M. MicroRNAs and the cell cycle. Biochim Biophys Acta Mol Basis Dis. 2011;1812:592-601.
199. Bartel DP. MicroRNA target recognition and regulatory functions. Cell. 2009;136:215-33.

200. Bartoszewski R, Sikorski AF. Editorial focus: understanding off-target effects as the key to successful RNAi therapy. Cell Mol Biol Lett. 2019:24:1-23.

201. Balasubramanian S, Gunasekaran K, Sasidharan S, Jeyamanickavel Mathan V, Perumal E. MicroRNAs and xenobiotic toxicity: an overview. Toxicol Rep. 2020;7:583-95.

202. Raisch J, Darfeuille-Michaud A, Nguyen HTT. Role of microRNAs in the immune system, inflammation and cancer. World J Gastroenterol. 2013;19:2985-96.

203. Fan J, Feng Y, Zhang R, et al. A simplified system for the effective expression and delivery of functional mature microRNAs in mammalian cells. Cancer Gene Ther. 2020;27:424-37.

204. Marsollier AC, Ciszewski L, Mariot V, Popplewell L, Voit T, Dickson G, Dumonceaux J. Antisense targeting of $3^{\prime}$ end elements involved in DUX4 mRNA processing is an efficient therapeutic strategy for facioscapulohumeral dystrophy: a new gene-silencing approach. Hum Mol Genet. 2016;25:1468-78.

205. Chen JCJ, King OD, Zhang Y, Clayton NP, Spencer C, Wentworth BM, Emerson CP, Wagner KR. Morpholino-mediated knockdown of DUX4 toward facioscapulohumeral muscular dystrophy therapeutics. Mol Ther. 2016;24:1405-11.

206. Ansseau E, Vanderplanck C, Wauters A, Harper SQ, Coppée F, Belayew A. Antisense oligonucleotides used to target the DUX4 mRNA as therapeutic approaches in faciosscapulohumeral muscular dystrophy (FSHD). Genes (Basel). 2017. https://doi.org/10.3390/genes8030093.

207. Lim KRQ, Maruyama R, Echigoya Y, et al. Inhibition of DUX4 expression with antisense LNA gapmers as a therapy for facioscapulohumeral muscular dystrophy. Proc Natl Acad Sci U S A. 2020;117:16509-15.

208. Lim KRQ, Maruyama R, Echigoya Y, et al. Correction for Lim et al., Inhibition of DUX4 expression with antisense LNA gapmers as a therapy for facioscapulohumeral muscular dystrophy. Proc Natl Acad Sci USA. 2020;117:21823.

209. Marrosu E, Ala P, Muntoni F, Zhou H. Gapmer antisense oligonucleotides suppress the mutant allele of COL6A3 and restore functional protein in ullrich muscular dystrophy. Mol Ther Nucleic Acids. 2017:8:416-27.

210. Touznik A, Maruyama R, Hosoki K, Echigoya Y, Yokota T. LNA/DNA mixmer-based antisense oligonucleotides correct alternative splicing of the SMN2 gene and restore SMN protein expression in type 1 SMA fibroblasts. Sci Rep. 2017;7:1-9.

211. DeVos SL, Miller TM. Antisense oligonucleotides: treating neurodegeneration at the level of RNA. Neurotherapeutics. 2013;10:486-97.

212. Stewart M. Polyadenylation and nuclear export of mRNAs. J Biol Chem. 2019;294:2977-87.

213. Rashnonejad A, Chermahini AG, Wallace L, Harper S. DUX4 mRNA silencing with CRISPR-Cas13 gene therapy as a prospective treatment for facioscapulohumeral muscular dystrophy (abstract only). Neuromuscul Disord. 2019;29:40.

214. Ciszewski L, Lu-Nguyen N, Slater A, Brennan A, Williams HEL, Dickson G, Searle MS, Popplewell L. G-quadruplex ligands mediate downregulation of DUX4 expression. Nucleic Acids Res. 2020;48:4179-94.

215. DeSimone AM, Leszyk J, Wagner K, Emerson CP. Identification of the hyaluronic acid pathway as a therapeutic target for facioscapulohumeral muscular dystrophy. Sci Adv. 2019. https://doi.org/10.1126/ sciadv.aaw7099.

216. Hsu CW, Huang R, Khuc T, et al. Identification of approved and investigational drugs that inhibit hypoxia-inducible factor-1 signaling Oncotarget. 2016;7:8172-83.

217. Sang N, Stiehl DP, Bohensky J, Leshchinsky I, Srinivas V, Caro J. MAPK signaling up-regulates the activity of hypoxia-inducible factors by its effects on p300. J Biol Chem. 2003;278:14013-9.

218. Bosnakovski D, Choi SH, Strasser JM, Toso EA, Walters MA, Kyba M. Highthroughput screening identifies inhibitors of DUX4-induced myoblast toxicity. Skelet Muscle. 2014. https://doi.org/10.1186/2044-5040-4-4.

219. Passerieux E, Hayot $M$, Jaussent $A$, et al. Effects of vitamin C, vitamin $E_{\text {, }}$ zinc gluconate, and selenomethionine supplementation on muscle function and oxidative stress biomarkers in patients with facioscapulohumeral dystrophy: a double-blind randomized controlled clinical trial. Free Radic Biol Med. 2015;81:158-69. 
220. Campbell K, Vowinckel J, Keller MA, Ralser M. Methionine metabolism alters oxidative stress resistance via the pentose phosphate pathway. Antioxid Redox Signal. 2016;24:543-7.

221. Joshi R, Adhikari S, Patro BS, Chattopadhyay S, Mukherjee T. Free radical scavenging behavior of folic acid: evidence for possible antioxidant activity. Free Radic Biol Med. 2001;30:1390-9.

222. van der Kooi EL, de Greef JC, Wohlgemuth M, Frants RR, van Asseldonk RJGP, Blom HJ, van Engelen BGM, van der Maarel SM, Padberg GW No effect of folic acid and methionine supplementation on D4Z4 methylation in patients with facioscapulohumeral muscular dystrophy. Neuromuscul Disord. 2006;16:766-9.

223. Sitzia C, Meregalli M, Belicchi M, Farini A, Arosio M, Bestetti D, Villa C, Valenti L, Brambilla P, Torrente Y. Preliminary evidences of safety and efficacy of flavonoids-And omega 3-based compound for muscular dystrophies treatment: a randomized double-blind placebo controlled pilot clinical trial. Front Neurol. 2019. https://doi.org/10.3389/fneur 2019.00755.

224. Voet NBM, van der Kooi EL, van Engelen BGM, Geurts ACH. Strength training and aerobic exercise training for muscle disease. Cochrane Database Syst Rev. 2019. https://doi.org/10.1002/14651858.CD003907. pub5.

225. Holloszy JO. The biology of aging. Mayo Clin Proc. 2000;75:218-218.

226. Friedrich-Baur-Institut (2020) Aktiv durch den Alltag-Bewegungsmöglichkeiten auch für Zuhause. Munich

227. Volpi E, Nazemi R, Fujita S. Muscle tissue changes with aging. Curr Opin Clin Nutr Metab Care. 2004;7:405-10.

228. Bostock EL, O'Dowd DN, Payton CJ, Smith D, Orme P, Edwards BT, Morse $\mathrm{Cl}$. The effects of resistance exercise training on strength and functional tasks in adults with limb-girdle, becker, and facioscapulohumeral dystrophies. Front Neurol. 2019. https://doi.org/10.3389/fneur.2019.01216.

229. Voet N. Rehabilitationsbehandlungen bei FSHD. 2018.

230. Voet N, Bleijenberg G, Hendriks J, De Groot I, Padberg G, Van Engelen B, Geurts A. Both aerobic exercise and cognitive-behavioral therapy reduce chronic fatigue in FSHD. Neurology. 2014;83:1914-22.
231. Bankolé L-C, Millet GY, Temesi J, et al. Safety and efficacy of a 6-month home-based exercise program in patients with facioscapulohumeral muscular dystrophy: a randomized controlled trial. Medicine (Baltimore). 2016;95:e4497

232. Ricci G, Ruggiero L, Vercelli $L$, et al. A novel clinical tool to classify facioscapulohumeral muscular dystrophy phenotypes. J Neurol. 2016:263:1204-14.

233. Ricci E, Galluzzi G, Deidda G, et al. Progress in the molecular diagnosis of facioscapulohumeral muscular dystrophy and correlation between the number of Kpnl repeats at the $4 \mathrm{q} 35$ locus and clinical phenotype. Ann Neurol. 1999:45:751-7.

234. Vercelli L, Mele F, Ruggiero L, et al. A 5-year clinical follow-up study from the Italian National Registry for FSHD. J Neurol. 2020. https://doi. org/10.1007/s00415-020-10144-7.

235. Lamperti C, Fabbri G, Vercelli L, et al. A standardized clinical evaluation of patients affected by facioscapulohumeral muscular dystrophy: the FSHD clinical score. Muscle Nerve. 2010;42:213-7.

236. Tawil R. Facioscapulohumeral muscular dystrophy. Neurotherapeutics. 2008;5:601-6.

237. Giannini S, Faldini C, Pagkrati S, Grandi G, Digennaro V, Luciani D, Merlini L. Fixation of winged scapula in facioscapulohumeral muscular dystrophy. Clin Med Res. 2007;5:155-62.

238. Scionti I, Greco F, Ricci G, et al. Large-scale population analysis challenges the current criteria for the molecular diagnosis of fascioscapulohumeral muscular dystrophy. Am J Hum Genet. 2012;90:628-35.

239. FSHD Society. Symptoms of FSHD. 2020.

240. Microsynth AG. THE SWISS DNA COMPANY Flyer DNA/RNA oligo synthesis. Locked Nucleic Acid (LNA). 2020

241. QIAGEN ${ }^{\circledR}$. Antisense LNA ${ }^{\circledR}$ GapmeRs Handbook. 2017.

\section{Publisher's Note}

Springer Nature remains neutral with regard to jurisdictional claims in published maps and institutional affiliations.
Ready to submit your research? Choose BMC and benefit from:

- fast, convenient online submission

- thorough peer review by experienced researchers in your field

- rapid publication on acceptance

- support for research data, including large and complex data types

- gold Open Access which fosters wider collaboration and increased citations

- maximum visibility for your research: over $100 \mathrm{M}$ website views per year

At BMC, research is always in progress.

Learn more biomedcentral.com/submissions 